University of Wollongong

Research Online

Australian Institute for Innovative Materials -

Papers

Australian Institute for Innovative Materials

$1-1-2019$

\title{
An efficient multi-doping strategy to enhance Li-ion conductivity in the garnet-type solid electrolyte Li7La3Zr2012
}

\author{
Yedukondalu Meesala \\ National Taiwan University \\ Yu-Kai Liao \\ National Taiwan Normal University \\ Anirudha Jena \\ National Taiwan University \\ Nai-Hsuan Yang \\ National Taiwan University \\ Wei Kong Pang \\ University of Wollongong, wkpang@uow.edu.au
}

See next page for additional authors

Follow this and additional works at: https://ro.uow.edu.au/aiimpapers

Part of the Engineering Commons, and the Physical Sciences and Mathematics Commons

Research Online is the open access institutional repository for the University of Wollongong. For further information contact the UOW Library: research-pubs@uow.edu.au 


\title{
An efficient multi-doping strategy to enhance Li-ion conductivity in the garnet- type solid electrolyte Li7La3Zr2012
}

\author{
Abstract \\ Lithium-ion $(\mathrm{Li}+)$ batteries suffer from problems caused by the chemical instability of their organic \\ electrolytes. Solid-state electrolytes that exhibit high ionic conductivities and are stable to lithium metal \\ are potential replacements for flammable organic electrolytes. Garnet-type Li $7 \mathrm{La} 3 \mathrm{Zr} 2012$ is a \\ promising solid-state electrolyte for next-generation solid-state Li batteries. In this study, we prepared \\ mono-, dual-, and ternary-doped lithium ( $\mathrm{Li}$ ) garnets by doping tantalum (Ta), tantalum-barium (Ta-Ba), and \\ tantalum-barium-gallium (Ta-Ba-Ga) ions, along with an undoped Li 7 La 3 Zr 2012 (LLZO) cubic garnet \\ electrolyte, using a conventional solid-state reaction method. The effect of multi-ion doping on the $\mathrm{Li}+$ \\ dynamics in the garnet-type LLZO was studied by combining joint Rietveld refinement against X-ray \\ diffraction and high-resolution neutron powder diffraction analyses with the results of Raman \\ spectroscopy, scanning electron microscopy, energy-dispersive X-ray spectroscopy, and multinuclear \\ magic angle spinning nuclear magnetic resonance. Our results revealed that $\mathrm{Li}+$ occupancy in the \\ tetrahedrally coordinated site (24d) increased with increased multi-ion doping in LLZO, whereas Li + \\ occupancy in the octahedrally coordinated site $(96 \mathrm{~h})$ remained constant. Among the investigated \\ compounds, the ternary-doped garnet structure Li $6.65 \mathrm{Ga} 0.05 \mathrm{La} 2.95 \mathrm{Ba} 0.05 \mathrm{Zr} 1.75 \mathrm{Ta} 0.25012$ \\ (LGLBZTO) exhibited the highest total ionic conductivity of 0.72 and $1.24 \mathrm{mS} \mathrm{cm} \mathrm{-1}$ at room temperature \\ and $60^{\circ} \mathrm{C}$, respectively. Overall, our findings revealed that the dense microstructure and increased $\mathrm{Li}+$ \\ occupancy in the tetrahedral-24d Li1 site played a key role in achieving the maximum room-temperature \\ Li-ion conductivity in the ternary-doped LGLBZTO garnet, and that the prepared ternary-doped LGLBZTO \\ was a potential solid electrolyte for Li-ion batteries without polymer adhesion.

\section{Disciplines} \\ Engineering | Physical Sciences and Mathematics

\section{Publication Details} \\ Meesala, Y., Liao, Y., Jena, A., Yang, N., Pang, W., Hu, S., Chang, H., Liu, C., Liao, S., Chen, J., Guo, X. \& Liu, R. \\ (2019). An efficient multi-doping strategy to enhance Li-ion conductivity in the garnet-type solid electrolyte \\ Li7La3Zr2012. Journal of Materials Chemistry A, 7 (14), 8589-8601.
}

\section{Authors}

Yedukondalu Meesala, Yu-Kai Liao, Anirudha Jena, Nai-Hsuan Yang, Wei Kong Pang, Shu-Fen Hu, Ho Chang, Chia-Erh Liu, Shih-Chieh Liao, Jin-Ming Chen, Xiangxin Guo, and Ru-Shi Liu 


\section{An efficient multi-doping strategy to enhance Li-ion conductivity in garnet-type solid electrolyte $\mathrm{Li}_{7} \mathrm{La}_{3} \mathrm{Zr}_{2} \mathrm{O}_{12}$}

Yedukondalu Meesala, ${ }^{\mathrm{a}}$ Yu-Kai Liao, ${ }^{\mathrm{b}}$ Anirudha Jena, ${ }^{\text {ac }}$ Nai-Hsuan Yang, ${ }^{\mathrm{a}}$ Wei Kong Pang, ${ }^{\mathrm{d}}$ Shu-Fen Hu, ${ }^{\text {b }}$ Ho Chang, ${ }^{\mathrm{c}}$ Chia-Erh Liu, ${ }^{\mathrm{e}}$ Shih-Chieh Liao, ${ }^{\mathrm{e}}$ Jin-Ming Chen, ${ }^{\mathrm{e}}$ Xiangxin Guo*f and Ru-Shi Liu*ac

${ }^{a}$ Department of Chemistry, National Taiwan University, Taipei 106, Taiwan bDepartment of Physics, National Taiwan Normal University, Taipei 116, Taiwan ${ }^{c}$ Department of Mechanical Engineering and Graduate Institute of Manufacturing Technology, National Taipei University of Technology, Taipei 106, Taiwan

${ }^{d}$ Institute for Superconducting \& Electronic Materials, University of Wollongong, NSW 2522, Australia

'Material and Chemical Research Laboratories, Industrial Technology Research Institute, Hsinchu 300, Taiwan

fCollege of Physics, Qingdao University, Qingdao 266071, China

\section{AUTHOR INFORMATION}

\section{*Corresponding authors}

E-mails: rsliu@ntu.edu.tw (R. S. Liu)

f10381@ntut.edu.tw (H. Chang)

sfhu.hu@gmail.com (S. F. Hu)

xxguo@qdu.edu.cn (X. Guo) 


\section{ABSTRACT}

Lithium-ion $\left(\mathrm{Li}^{+}\right)$batteries suffer from problems caused by the chemical instability of their organic electrolyte. Solid-state electrolytes that exhibit high ionic conductivities and stable to lithium metal are potential replacements for flammable organic electrolytes. Garnet-type $\mathrm{Li}_{7} \mathrm{La}_{3} \mathrm{Zr}_{2} \mathrm{O}_{12}$ is a promising solid-state electrolyte for next-generation solidstate Li batteries. In this study, we prepared mono-, dual-, and ternary-doped lithium (Li) garnets by doping tantalum (Ta), tantalum-barium (Ta-Ba), and tantalum-bariumgallium (Ta-Ba-Ga) ions, along with undoped-Li근 $\mathrm{La}_{3} \mathrm{Zr}_{2} \mathrm{O}_{12}$ (LLZO) cubic garnet electrolyte, using a conventional solid-state reaction method. The effect of multi-ion doping on the $\mathrm{Li}^{+}$dynamics in the garnet-type LLZO was studied by combining analyses of joint Rietveld refinement against X-ray diffraction and high-resolution neutron powder diffraction with the results of Raman spectroscopy, scanning electron microscopy, energy-dispersive X-ray spectroscopy, and multinuclear magic angle spinning nuclear magnetic resonance. Our results revealed that $\mathrm{Li}^{+}$occupancy in the tetrahedrally coordinated site (24d) increased with increased multi-ion doping in LLZO, whereas $\mathrm{Li}^{+}$ occupancy in the octahedrally coordinated site (96h) remained constant. Among the

investigated compounds, the ternary-doped garnet structure $\mathrm{Li}_{6.65} \mathrm{Ga}_{0.05} \mathrm{La}_{2.95} \mathrm{Ba}_{0.05} \mathrm{Zr}_{1.75} \mathrm{Ta}_{0.25} \mathrm{O}_{12}$ (LGLBZTO) exhibited the highest total ionic conductivity of 0.72 and $1.24 \mathrm{mS} \mathrm{cm}^{-1}$ at room temperature and $60{ }^{\circ} \mathrm{C}$, respectively. Overall, our findings revealed that the dense microstructure and increased $\mathrm{Li}^{+}$occupancy in the tetrahedral- $24 d_{\mathrm{Li1}}$ site played a key role in achieving the maximum roomtemperature Li-ion conductivity in ternary-doped LGLBZTO garnet, and that the 
prepared ternary-doped LGLBZTO was a potential solid electrolyte for Li-ion batteries without polymer adhesion. 


\section{Introduction}

Inorganic solid-state electrolytes (SEs) for all-solid-state Li-ion batteries (ASSLIB) are promising replacements for the flammable, toxic, flowing, and volatile organic liquidbased electrolytes due to their great safety, high performance, and reliability. ${ }^{1,} 2$ Moreover, SEs are sufficiently stable in contact with $\mathrm{Li}$ metal, which can address the well-known problems in conventional batteries, such as explosion hazards by an internal short circuit (dendrites) and thermal runway. ${ }^{3,4}$ However, the challenge is in the design of appropriate solid electrolyte with high ionic conductivity $\left(>10^{-4} \mathrm{~S} \mathrm{~cm}^{-1}\right)$, negligible electronic conductivity, and good electrochemical stability. ${ }^{5-8}$ The garnet-like material of the stoichiometry $\mathrm{Li}_{7} \mathrm{La}_{3} \mathrm{Zr}_{2} \mathrm{O}_{12}$ (LLZO) was first discovered as a fast $\mathrm{Li}^{+}$conductor by Murugan et al. in 2007. ${ }^{9}$ The LLZO SE material has been a research hotspot due to its relatively high Li-ion conductivity $\left(2 \times 10^{-4} \mathrm{~S} \mathrm{~cm}^{-1}\right)$ at room temperature, wide electrochemical window (> $5 \mathrm{~V}$ vs. $\mathrm{Li}^{+} / \mathrm{Li}$ ), and good compatibility with $\mathrm{Li}$ anodes. ${ }^{10,11}$ However, LLZO is crystallized in two polymorphs: a thermodynamically stable tetragonal polymorph with ordered $\mathrm{Li}^{+}$distribution (space group: $I 4_{1} /$ acd, No. 142$)^{12}$ and a high-temperature stable cubic polymorph with highly disordered $\mathrm{Li}^{+}$distribution

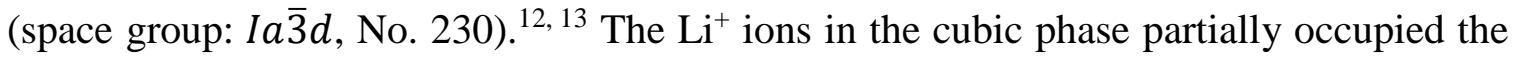
tetrahedral-24d $d_{\mathrm{Li} 1}$ and distorted octahedral-96h $h_{\mathrm{Li} 2}$ sites, whereas the $\mathrm{Li}^{+}$ions in the tetragonal polymorph fully occupied three crystallographic sites: tetrahedral-8a (Li1), distorted octahedral-16f $(\mathrm{Li} 2)$, and $32 g(\mathrm{Li} 3){ }^{12,13}$ As a result of the disordered $\mathrm{Li}^{+}$ distribution and partial occupation in cubic phase, the Li-ion conductivity of the cubic phase is about two orders of magnitude higher than that of the tetragonal counterpart at room temperature. ${ }^{14,15}$ Hence, many studies focused on the optimization of the garnet 
cubic phase by promoting $\mathrm{Li}^{+}$disorder framework and on the improvement of the Li-ion conductivity (ranging from $\sim 10^{-4} \mathrm{~S} \mathrm{~cm}^{-1}$ to $10^{-3} \mathrm{~S} \mathrm{~cm}^{-1}$ ) at room temperature. ${ }^{6}$ Geiger et al. noticed the highly conductive cubic polymorph along with the tetragonal polymorph when LLZO was synthesized in an Al-containing crucible; An LLZO sintered in a Ptcrucible yielded a solely tetragonal phase. ${ }^{16}$ They argued that the unintentional doping of $\mathrm{Al}$ from the crucible into the LLZO framework at the Li site during the high-temperature sintering stabilized the cubic polymorph. Many studies investigated the role of $\mathrm{Al}$ in achieving a fast-ionic cubic conductor by intentionally adding $\mathrm{Al}$ into the LLZO garnet during the synthesis. ${ }^{14}, 17-19$ However, the preferential site (tetrahedral-24d $d_{\text {Li1 }}$ or octahedral-96h $h_{\mathrm{Li2}}$ sites) for $\mathrm{Al}$ ions remains unclear. The formation of highly conducting cubic polymorph from alumina crucible often requires high sintering temperatures $\left(>1200^{\circ} \mathrm{C}\right)$ and long sintering time, which may cause substantial Li loss from the sample. ${ }^{20,21}$ A trivalent doping cation $\left(\mathrm{Ga}^{3+}\right)$, as a substitute for $\mathrm{Li}^{+}$, was found to stabilize the similar cubic phase and improve the Li-ion conductivities compared with $\mathrm{Al}^{3+} .22$, ${ }^{23}$ Moreover, Ga doping can stabilize the cubic phase at a low synthesis temperature of about $1000{ }^{\circ} \mathrm{C}$ (sintering temperature is about $1100{ }^{\circ} \mathrm{C}$ ). ${ }^{24}$

Recent studies demonstrated that doping of supervalent-cation $\left(\mathrm{Ta}^{5+}, \mathrm{Nb}^{5+}, \mathrm{Sb}^{5+}\right.$, and $\mathrm{Bi}^{5+}$ at the $\mathrm{Zr}^{4+}$ site) into the garnet-type LLZO remarkably improved the Li-ion conductivities at room temperature. ${ }^{25-29}$ The doping alters the structure by creating $\mathrm{Li}^{+}$ vacancies for charge neutrality and by increasing the disorderliness in the framework, thereby promoting the stabilization of the highly conductive cubic phase. In contrast, partial substitution of low-valent alkaline earth metal cations $\left(\mathrm{Ca}^{2+}, \mathrm{Sr}^{2+}\right.$, and $\left.\mathrm{Ba}^{2+}\right)$ at the $\mathrm{La}^{3+}$ site in the LLZO garnet framework has a substantial effect on the Li-ion 
conductivities. ${ }^{30,31}$ Divalent doping at the La site increases the $\mathrm{Li}^{+}$concentration in the framework, which leads to improved Li-ion conductivities. Additionally, replacement of $\mathrm{La}^{3+}$ by large size dopant ions expands the lattice, enlarging the bottleneck size for $\mathrm{Li}^{+}$ migration, thereby increasing the Li-ion conductivities. ${ }^{32}$ In strategic doping in the LLZO garnet, each doping ion has an important role in modifying the garnet framework. Thus, choosing the doping ion can effectively enhance the Li-ion conductivity in LLZO. Recently, simultaneous multi-doping strategy on LLZO resulted in enhanced ionic conductivity (ranging from $\sim 10^{-4} \mathrm{~cm}^{-1}$ to $10^{-3} \mathrm{~S} \mathrm{~cm}^{-1}$ ) at room temperature. ${ }^{33}$ However, further endeavors are still needed to investigate the site preference and role of each dopant ion with respect to the $\mathrm{Li}^{+}$dynamics in doped LLZO systems. We aim to identify the preferred site of the dopant ion, preferred Li occupancy in the $24 d_{\mathrm{Li} 1} / 96 h_{\mathrm{Li} 2}$ sites, and the role of the dopant in the Li-ion conduction by using neutron diffraction techniques.

Therefore, in this paper, we used the multi-doping strategy for tuning the conductivity of LLZO by substituting aliovalent ions (e.g., partial substitution of $\mathrm{Li}^{+}$by $\mathrm{Ga}^{3+}, \mathrm{La}^{3+}$ by $\mathrm{Ba}^{2+}$, and $\mathrm{Zr}^{4+}$ by $\mathrm{Ta}^{5+}$ ) on LLZO. The effects of the doping ion on the $\mathrm{Li}^{+}$ mobility and Li-ion conductivity were investigated via joint Rietveld refinement against Xray diffraction (XRD) and high-resolution neutron powder diffraction (NPD) analysis that conclusively gives information on Li occupancy. Such a joint analysis, together with the results of Raman and solid-state nuclear magnetic resonance (NMR) spectroscopies, scanning electron microscopy (SEM), and energy-dispersive X-ray spectroscopy (EDX). The simultaneous multi-doping approach has the potential to improve the Li-ion conductivity in LLZO. The prepared garnet-type electrolyte was successfully tested in ASSLIBs with LFP as the cathode. 


\section{Experimental section}

\section{Solid electrolyte synthesis}

Preparation of multi-doped Solid Electrolytes. A series of unsubstituted $\mathrm{Li}_{7} \mathrm{La}_{3} \mathrm{Zr}_{2} \mathrm{O}_{12}$ (undoped LLZO), mono-substituted $\mathrm{Li}_{6.75} \mathrm{La}_{3} \mathrm{Zr}_{1.75} \mathrm{Ta}_{0.25} \mathrm{O}_{12}$ (mono-doped LLZTO), dual-substituted $\mathrm{Li}_{6.8} \mathrm{La}_{2.95} \mathrm{Ba}_{0.05} \mathrm{Zr}_{1.75} \mathrm{Ta}_{0.25} \mathrm{O}_{12}$ (dual-doped LLBZTO), and ternary-substituted $\mathrm{Li}_{6.65} \mathrm{Ga}_{0.05} \mathrm{La}_{2.95} \mathrm{Ba}_{0.05} \mathrm{Zr}_{1.75} \mathrm{Ta}_{0.25} \mathrm{O}_{12} \quad$ (ternary-doped LGLBZTO) samples were synthesized through a solid-state reaction. LiOH (98\%, Alfa Aesar; preheated at $200{ }^{\circ} \mathrm{C}$ for $6 \mathrm{~h}$ ), $\mathrm{La}_{2} \mathrm{O}_{3}$ (99.9\%, Sigma-Aldrich; preheated at $900{ }^{\circ} \mathrm{C}$ for 12 h), $\mathrm{ZrO}_{2}$ (99.7\%, Alfa Aesar), $\mathrm{Al}_{2} \mathrm{O}_{3}$ (1 wt\% LLZO, 99.95\%, Sigma-Aldrich), $\mathrm{Ga}_{2} \mathrm{O}_{3}$ (99.0\%, Sigma-Aldrich), $\mathrm{BaCO}_{3}$ (99.0\%, Sigma-Aldrich), and $\mathrm{Ta}_{2} \mathrm{O}_{5}$ (99.0\%, SigmaAldrich) were used as reagents. The raw materials were weighed based on stoichiometric quantities with an excess of $10 \mathrm{wt} \% \mathrm{LiOH}$ to compensate for the possible loss of $\mathrm{Li}^{+}$vapored components during sintering. The reagents were carefully mixed with isopropyl alcohol and ball milled for $12 \mathrm{~h}$ in a Teflon jar by using zirconia balls at $300 \mathrm{rpm}$ for homogenization. The homogeneous slurry was transferred to an alumina crucible and dried at $80^{\circ} \mathrm{C}$ overnight to evaporate the solvent. The well-mixed dried powder was ground and then cold pressed into pellets by using a uniaxial press. The resulting pellets were placed in an alumina crucible and heated at $900^{\circ} \mathrm{C}$ for $12 \mathrm{~h}$ followed by ball milling for another $12 \mathrm{~h}$ to obtain the cubic phase. The cubic powders were pelletized by both uniaxially cold pressing at $1734 \mathrm{MPa}$ and hot-pressing at $1000{ }^{\circ} \mathrm{C}$ and $40 \mathrm{MPa}$. The calcined cubic phase powder was ground by agate mortar and then uniaxially pressed into pellets with a diameter of $12 \mathrm{~mm}$ and thickness of $2 \mathrm{~mm}$ at $1734 \mathrm{MPa}$. The pellets were covered with a thick layer of the same composition of powder to prevent Li evaporation 
and avoid $\mathrm{Al}^{3+}$ diffusion from crucibles followed by multistep sintering to acquire a dense and pure cubic phase. This multistep sintering process involved heating up to $900{ }^{\circ} \mathrm{C}$ at $5{ }^{\circ} \mathrm{C} / \mathrm{min}$ and holding for $4 \mathrm{~h}$ and then further heating to $1130{ }^{\circ} \mathrm{C}$ at $5{ }^{\circ} \mathrm{C} / \mathrm{min}$ and holding for $18 \mathrm{~h}$ before cooling to room temperature. All thermal processes were performed under atmospheric conditions by using $\mathrm{Al}_{2} \mathrm{O}_{3}$ crucibles. After the final thermal treatment, the pellets were stored in an argon-filled glovebox to prevent the possible contamination by carbon dioxide and moisture, which can affect the electrochemical properties. A $30 \mathrm{~mm}$ diameter, $3 \mathrm{~mm}$ thick doped, hot-pressed LLZO pellets were prepared by loading cubic powders into a graphite die with the support of carbon paper around the die wall, which were hot-pressed at $900{ }^{\circ} \mathrm{C}$ for $30 \mathrm{~min}$ and at $1000{ }^{\circ} \mathrm{C}$ for $1 \mathrm{~h}$ under $40 \mathrm{MPa}$ pressure by flowing argon atmosphere. Hot-pressed samples were subjected to lower temperature than uniaxially cold-pressed sintered samples. The cooled pellets from the hot-press were again heated at $1000{ }^{\circ} \mathrm{C}$ for $4 \mathrm{~h}$ in atmospheric air to remove the residual graphite. After heating, the pellet was freed from residual graphite and appeared in bright white color. The pellet was cut into $10 \mathrm{~mm}$ diameter and $1 \mathrm{~mm}$-thick disk by using a diamond saw in mineral oil. For the electrochemical measurements, the pellets were polished on both sides to a mirror-polished surface by using 600-, 1200-, and 2000-grit SiC sandpaper.

\section{Density and Structure Characterization}

The ceramic density values were obtained through the Archimedes method with water for measurement. The ceramic densities of the pellets were estimated based on a theoretical density of $5.107 \mathrm{~g} \mathrm{~cm}^{-3}$. The phase purity of the doped LLZO powder sintered at $900{ }^{\circ} \mathrm{C}$ and the multi-sintered pellets at different temperatures was determined using X-ray powder diffraction (XRD) through a Bruker D2 Phaser with $\mathrm{CuK} \alpha$ radiation $(\lambda=$ 
$1.5405 \AA$ ). All diffraction patterns were recorded in the range of $10^{\circ}<2 \theta<80^{\circ}$ with a step size of $0.015^{\circ}$. The applied voltage and current were at $30 \mathrm{kV}$ and $30 \mathrm{~mA}$, respectively. The Synchrotron X-ray powder diffraction (SXRD) patterns recorded from the 01C2 beamline with $25 \mathrm{keV}$ X-rays at the National Synchrotron Radiation Research Center in Taiwan. An X-ray with a wavelength of 0.774916 (1) $\AA$ was used, and the data were recorded between $5^{\circ}<2 \theta<45^{\circ}$. Neutron powder diffraction (NPD) data were obtained using the beamline ECHIDNA at the Australian Nuclear Science and Technology Organization. The neutron beam wavelength was determined to be 1.62362(4) $\AA$ using the $\mathrm{La}^{11} \mathrm{~B}_{6}$ NIST standard reference material (SRM660b). GSAS software was employed to analyze the NPD data. The Al occupancy at the tetrahedral24d site was fixed at 0.06 , which is close to the theoretical value derived from 1 wt.\% addition of $\mathrm{Al}_{2} \mathrm{O}_{3} .{ }^{20}$ The morphologies and microstructures of the doped LLZO pellets were analyzed by field-emission scanning electron microscopy (FE-SEM) system by operating JEOL JSM-7610F at $15 \mathrm{kV}$. The samples were platinum-sputtered to eliminate any charge effect. The elemental composition and the presence of all common elements were obtained using energy dispersive X-ray spectroscopy (EDS). The mirror-polished pellets were gently broken into small pieces in an argon-filled glovebox and quickly moved for the analysis to minimize air exposure. To obtain a more detailed structural information around $\mathrm{Li}$ and $\mathrm{Ga}$ environments, ${ }^{7} \mathrm{Li}$ and ${ }^{71} \mathrm{Ga}$ MAS NMR data were collected, respectively, at room temperature by using a Bruker Avance III spectrometer equipped with a $3.2 \mathrm{~mm}$ MAS probe head. The frequencies used for the ${ }^{7} \mathrm{Li}$ and ${ }^{71} \mathrm{Ga}$ nuclei were at 155.5 and $121.951 \mathrm{MHz}$, respectively, by applying an external magnetic field of $14.1 \mathrm{~T}$. The spinning speed of the samples was $12 \mathrm{kHz}$, and spectra were recorded 
after a single pulse irradiation $(2-6 \mu \mathrm{s})$. The chemical shifts of ${ }^{7} \mathrm{Li}$ and ${ }^{71} \mathrm{Ga}$ were calibrated with $1 \mathrm{M} \mathrm{LiCl}$ and $\mathrm{Ga}\left(\mathrm{NO}_{3}\right)_{3}$, respectively. The spinning rate, position, line width, and intensity of components were automatically determined.

\section{Conductivity Measurements}

The AC impedance of the SEs was determined using a Solartron SI1260 impedance/gainphase analyzer in the frequency range of $10 \mathrm{MHz}$ to $0.1 \mathrm{~Hz}$, with a signal amplitude of $0.1 \mathrm{~V}$. All the doped LLZO pellets used in the electrochemical measurements have a thickness of 1.0-2.0 mm unless otherwise specified. The mirror-polished pellets were sputtered with $\mathrm{Au}$ as the blocking electrode on both sides and placed into a Swagelok cell in Au|LLZO|Au configuration for electrochemical studies. The assembled cell was then connected with electrical wires to the impedance spectrometer. To measure the conductivity versus temperature, the AC impedance of the cells was measured from 20$120^{\circ} \mathrm{C}$. The cell was equilibrated for $1 \mathrm{~h}$ at each measurement. The impedance data were analyzed using Z Plot and Z View software packages. All impedance data were fitted with an equivalent circuit of the R(R//CPE)(R//CPE) model.

\section{Fabrication of All-Solid-State Li-Ion Batteries}

A cathode slurry was prepared by mixing $\mathrm{LiFePO}_{4}$, polyvinylidene fluoride (PVDF), KS6 carbon black, and bis-trifluoromethane sulfonamide (LiTFSI) as a lithium salt in the weight ratio of 10:2:1:7 by using an appropriate amount of NMP. ${ }^{34}$ Notably, the mixture of Li salt (LiTFSI) and the binder (PVDF) can form a polymer electrolyte. ${ }^{35}$ The slurry was homogenously ground using a mortar and pestle for $30 \mathrm{~min}$. The well-mixed slurry was spread equally on one side of a SE pellet followed by vacuum drying at $120^{\circ} \mathrm{C}$ for 
$12 \mathrm{~h}$. On the other side of the SE pellet was the pressed Li foil (thickness of around 20 $\mu \mathrm{m})$ as a negative electrode. The active material loading of the cathode was $2-3 \mathrm{mg} \mathrm{cm}^{-2}$.

\section{Electrochemical Measurements}

For the electrochemical studies, the SE pellet with Li foil was sealed in a Swagelok cell in an argon glovebox. The cell was tested at room temperature between 2.7 and $3.8 \mathrm{~V}$ by using a potentiostat/galvanostat (Arbin BT2000) under open-air condition.

\section{Results and discussion}

The synthesized LLZO powders calcined at $900{ }^{\circ} \mathrm{C}$ for $12 \mathrm{~h}$, uniaxially pressed pellets sintered at $1130{ }^{\circ} \mathrm{C}$ for $18 \mathrm{~h}$, and hot-pressed pellets at $1100{ }^{\circ} \mathrm{C}$ for $1 \mathrm{~h}$ were analyzed via X-ray diffraction (XRD) using CuKa radiation in the range of $10^{\circ}<2 \theta<80^{\circ}$ with a step size of $0.015^{\circ}$. Fig. 1 shows the room temperature XRD data for the $\mathrm{Li}_{7} \mathrm{La}_{3} \mathrm{Zr}_{2} \mathrm{O}_{12}$

(undoped $\quad$ LLZO), $\quad \mathrm{Li}_{6.75} \mathrm{La}_{3} \mathrm{Zr}_{1.75} \mathrm{Ta}_{0.25} \mathrm{O}_{12} \quad$ (mono-doped $\quad$ LLZTO), $\begin{array}{lll}\mathrm{Li}_{6.8} \mathrm{La}_{2.95} \mathrm{Ba}_{0.05} \mathrm{Zr}_{1.75} \mathrm{Ta}_{0.25} \mathrm{O}_{12} & \text { (dual-doped } & \text { LLBZTO), }\end{array}$ $\mathrm{Li}_{6.65} \mathrm{Ga}_{0.05} \mathrm{La}_{2.95} \mathrm{Ba}_{0.05} \mathrm{Zr}_{1.75} \mathrm{Ta}_{0.25} \mathrm{O}_{12}$ (ternary-doped LGLBZTO) powders after calcination at $900{ }^{\circ} \mathrm{C}$ for $12 \mathrm{~h}$. XRD analysis revealed that all the diffraction peaks of the undoped LLZO and multi-doped LLZOs powders were well indexed with the standard compound (garnet-type with cubic structure $\mathrm{Li}_{5} \mathrm{La}_{3} \mathrm{Nb}_{2} \mathrm{O}_{12}$ (PDF45-0109)), indicating that the garnet framework can accommodate aliovalent ions of different sizes in the multidoped LLZO structure without modifying the symmetry. ${ }^{16,36}$ By contrast, additional weak diffraction peaks corresponding to a minor impurity phase ( $\left.\mathrm{LiAlO}_{2}, \mathrm{PDF} 73-1338\right)$ were observed only for the undoped LLZO sample, which may be due to the addition of Al during the synthesis. However, no other peaks were observed for the mono-doped 
LLZTO, dual-doped LLBZTO, and ternary-doped LGLBZTO samples. Doping of supervalent $\mathrm{Ta}^{5+}$ and $\mathrm{Ga}^{3+}$ and low-valent $\mathrm{Ba}^{2+}$ at the $\mathrm{Zr}^{4+}, \mathrm{Li}^{+}$, and $\mathrm{La}^{3+}$ sites, respectively, into the garnet structure led to disordered structure, either by creating or filling $\mathrm{Li}^{+}$vacancies to form pure cubic phase without any tetragonal or other detectable impurities. In the close inspection of XRD, the peaks between $25^{\circ}-32^{\circ}$ shifted with multi-ion doping (Fig. 1b). For the mono-doped LLZTO, the diffraction peaks slightly shifted toward higher angles, suggesting a decrease in both the $\mathrm{Li}^{+}$concentration and lattice constants with increased $\mathrm{Ta}^{5+}$ doping at the $\mathrm{Zr}^{4+}$ site. Compared with undoped LLZO, the diffraction peaks for dual-doped LLBZTO and ternary-doped LGLBZTO shifted toward lower angles, which indicated increased lattice parameters. In general, the intensity of the diffraction peaks reduces significantly with the increase in dopant concentration, indicating a loss of crystallinity due to lattice distortion. Multi-doping of larger size dopant ions into the garnet framework expands the lattice size and induces a strain into the system. As can be seen from the XRD patterns of multi-doped LLZOs (Fig. 1), the diffraction peaks get broadened with doping, suggesting a significant lattice-defect formation by multi-ion doping. The lattice parameters were evaluated using both XRD and NPD Rietveld refined analysis (vide infra). The diffraction peaks widened with increased multi-ion doping in LLZO. The Rietveld refinements of the XRD patterns of the analyzed samples are shown in Fig. S1-S4. $\dagger$ The XRD refined crystallographic parameters are summarized in Table S1†. During structure Rietveld refinement, zero shift error, background parameters, absorption correction parameters, occupation parameters, histogram scale factors, pseudo-Voigt coefficient, and lattice constants were refined followed by the atomic displacement parameters. Then, isotropic thermal parameters 
were freely refined. Refinement results revealed that all the garnet samples were indexed in a highly conductive cubic phase with the space group of $I a \overline{3} d$ and the lattice constants agreed well with literature. ${ }^{9}$ The structure of a cubic LLZO unit cell with connectivity pattern of tetrahedral-24d $d_{\mathrm{Li} 1}$ and octahedral-96h $h_{\mathrm{Li} 2}$ sites projected on $2 \mathrm{D}$ is shown in Fig. 1c. The garnet-type cubic LLZO structure is composed of edge-sharing dodecahedral $\mathrm{La}(1) \mathrm{O}_{8}$ and $\mathrm{La}(2) \mathrm{O}_{8}$ units (green, $24 c$ site) occupied by $\mathrm{La}^{3+}$ at the central site and octahedral $\mathrm{ZrO}_{6}$ units (orange, $16 a$ site) occupied by $\mathrm{Zr}^{4+}$ at the central site. $\mathrm{Li}^{+}$ions are occupied in two crystallographic sites: tetrahedral- $24 d_{\mathrm{Li1}}$ sites represented by yellow spheres and distorted octahedral-96h $h_{\mathrm{Li} 2}$ sites represented by green spheres.

Raman measurements were performed on the undoped LLZO, mono-doped LLZTO, dual-doped LLBZTO, and ternary-doped LGLBZTO in the range of $100-1200 \mathrm{~cm}^{-1}$ at room temperature and results are shown in Fig. 2. In the Raman spectra, the low frequency region $\left(<300 \mathrm{~cm}^{-1}\right)$ vibrational bands can be assigned to $\mathrm{LiO}_{6}$ octahedral unit ( $96 h_{\mathrm{Li} 2}$ position); the middle-frequency region $\left(300-550 \mathrm{~cm}^{-1}\right)$ vibrational bending modes can be assigned to $\mathrm{LiO}_{4}$ tetrahedral unit ( $24 d_{\mathrm{Li1}}$ position), and the high-frequency region (> $550 \mathrm{~cm}^{-1}$ ) bands corresponded to the stretching mode of $\mathrm{ZrO}_{6}$ octahedral unit (16a position). ${ }^{37}$ The Raman spectra of the undoped and multi-doped LLZOs overlapped with the cubic phase of LLZO garnets reported in the literature. ${ }^{37-41}$ Tietz et al. reported that the band near $645 \mathrm{~cm}^{-1}$ corresponded to the stretching mode of the $\mathrm{ZrO}_{6}$ octahedral unit. ${ }^{37}$ Thompson et al. found an additional band near $750 \mathrm{~cm}^{-1}$ in $\mathrm{Li}_{6.5} \mathrm{La}_{3} \mathrm{Zr}_{1.5} \mathrm{Ta}_{0.5} \mathrm{O}_{12}$ under the partial substitution of $\mathrm{Zr}^{4+}$ with $\mathrm{Ta}^{5+} \cdot{ }^{39}$ They suggested that the additional band was attributed to the stretching mode of the $\mathrm{TaO}_{6}$ octahedral unit due to its increased intensity at a high $\mathrm{Ta}^{5+}$ concentration. In our investigation, for the multi-doped LLZOs, 
the stretching mode of the $\mathrm{Zr}-\mathrm{O}$ band and additional band corresponding to the Ta-O unit appeared at 625 and $720 \mathrm{~cm}^{-1}$, respectively. In the low region Raman spectra, the two narrow bands appeared below $200 \mathrm{~cm}^{-1}$ belonged to $\mathrm{Li}-\mathrm{O}$ bonding peaks of cubic LLZO garnet. Such peaks were split in a tetragonal LLZO due to the reduction in symmetry. The highly intense Raman peak that corresponds to the vibration mode of $\mathrm{CO}_{3}{ }^{2-}$ and generally appears at $1090 \mathrm{~cm}^{-1}$ was not observed in the undoped and multi-doped LLZOs; such finding indicated that the pellets were free from $\mathrm{Li}_{2} \mathrm{CO}_{3}{ }^{41}$

The ceramic densities of the undoped and multi-doped LLZO hot-press pellets were calculated using the formula $\rho_{\text {exp }} / \rho_{\text {theo, }}$, where $\rho_{\text {exp }}$ is the experimental density measured through the Archimedes method, and $\rho_{\text {theo }}$ is the theoretical density $\left(5.107 \mathrm{~g} \mathrm{~cm}^{-3}\right)$ of cubic LLZO. ${ }^{16}$ The $\rho_{\text {exp }}$ of the doped LLZO samples was measured by using Equation 1.

$$
\rho_{\text {exp }}=\frac{W_{\text {air }}}{W_{\text {air }}-W_{\text {water }}} \times \rho_{\text {water }}
$$

where $W_{\text {air }}$ is the weight of the doped LLZO sample in the air, $W_{\text {water }}$ is the weight of the doped LLZO sample in deionized water, and $\rho_{\text {water }}$ is the density of water. The hot-press pellets achieved high densities, and the density of either mono-doped LLZTO or multidoped LLBZTO and LGLBZTO approached the theoretical density (Table 1). The maximum reported density for the multi-doped LLZO pellets suggested rapid grain growth with multi-ion doping into the LLZO framework, which can be seen in the morphologies (Fig. S5†). The highly dense garnet material leads to improved ionic conductivities. Moreover, a microstructure with high density and without secondary phase is crucial in preventing the growth of Li dendrites in LIBs. ${ }^{42-44}$ 
The influence of doping multi-ions ( $\mathrm{Ga}, \mathrm{Ba}$, and $\mathrm{Ta}$ ) on the morphology of doped LLZO samples was examined using field emission scanning electron microscopy (FESEM). Fig. S5† shows the FE-SEM images of the undoped LLZO, mono-doped LLZTO, dual-doped LLBZTO, and ternary-doped LGLBZTO obtained at room temperature along with the optical image of LGLBZTO with $0.5 \mathrm{~mm}$ thickness. Substantial changes in the morphology of the microstructure were observed between the undoped LLZO and multidoped LLZO samples. The SEM image of the undoped LLZO revealed that the grains were not contacted well with each other. Furthermore, there were irregular pores among the grains, which is consistent with the low density of the undoped LLZO. By contrast, the SEM images of the mono-doped LLZTO and dual-doped LLBZTO exhibited dense and homogeneous morphology without any noticeable pores among the grains, which are reduced owing to their grain growth and mergence. A close inspection of the ternarydoped LGLBZTO revealed that mixtures of small and large grains were present in the microstructure. The microstructure appeared to be highly dense and compact by filling the gaps between large grains with small grains. This result corroborated the high density of the ternary-doped LGLBZTO, which was close to the theoretical density. The fabrication of differently sized grains by mixing large particles with small particles resulted in the dense microstructure. ${ }^{43}$ Almost no porosity was detected for the dualdoped LLBZTO and ternary-doped LGLBZTO. Hence, multi-doped LLZOs are expected to exhibit high Li-ion conductivities. The letters "LGLBZTO" behind the pellet can be seen clearly that indicates the translucent nature of the pellet with reduced grain boundaries. The particle size distributions for the undoped LLZO, mono-doped LLZTO, dual-doped LLBZTO, and ternary-doped LGLBZTO were measured at room 
temperature. The $d(0.1), d(0.5)$, and $d(0.9)$ of the undoped and multi-doped LLZOs particles substantiated the SEM microstructure (Table S2†).

EDX mapping was carried out for the undoped LLZO, mono-doped LLZTO, dualdoped LLBZTO, and ternary-doped LGLBZTO samples to detect the respective dopants and their composition on grains and grain boundaries (Fig. 3). EDX analysis revealed that the $\mathrm{Al}$ was exclusively found in the undoped LLZO sample at the grain boundaries. The localization of $\mathrm{O}, \mathrm{La}, \mathrm{Zr}$, and dopant ions ( $\mathrm{Ta}, \mathrm{Ba}$, and $\mathrm{Ga}$ ) was uniformly distributed among the crystal grains. Furthermore, a predominant distribution of $\mathrm{Ga}$, Ba, and Ta was observed mainly inside the grains in the EDX maps, which confirmed the inclusion of dopant ions in the garnet lattice.

To study the effect of doping on $\mathrm{Li}^{+}$transportation, the ionic conductivities of the undoped LLZO, mono-doped LLZTO, dual-doped LLBZTO, and ternary-doped LGLBZTO were measured using the AC impedance technique with Au as the blocking electrode. A typical Nyquist impedance plot for the ternary-doped LGLBZTO ( $\left.\mathrm{Li}_{6.65} \mathrm{Ga}_{0.05} \mathrm{La}_{2.95} \mathrm{Ba}_{0.05} \mathrm{Zr}_{1.75} \mathrm{Ta}_{0.25} \mathrm{O}_{12}\right)$ with $\mathrm{Au}|\mathrm{LGLBZTO}| \mathrm{Au}$ configuration was recorded at room temperature (Fig. 4a). The undoped LLZO, mono-doped LLZTO, dualdoped LLBZTO, and ternary-doped LGLBZTO all showed one partially depressed semicircle at the high-frequency region with a low-frequency diffusion spike. This semicircle can be assigned as the total impedance, including the contribution from bulk and grain boundary impedances, and the low-frequency spike can be attributed to $\mathrm{Li}^{+}$ blocking at the electrode/electrolyte interface. The impedance data were fitted using an equivalent circuit model consisting of $\left(R_{b}\right)\left(R_{g b} C P E_{g b}\right)(C P E)$. The right intercept of the semicircle on the real axis at the high-frequency region represents the bulk resistance of 
the sample, which was denoted as $R_{b}$ in the equivalent circuit. $R_{g b}$ was referred as grain boundary resistance; $C P E_{g b}$ and $C P E$ were referred as the constant phase element contributions attributed to the grain boundary capacitance, and the diffusion capacitance at the electrode/electrolyte interface, respectively. The diameter of the semicircle at the middle frequency corresponded to the total resistance, which is the sum of the resistance of the grain and grain boundary response $\left(R_{b}+R_{g b}\right)$. The contributions of grain and grain boundary responses were difficult to distinguish from the impedance spectra. The total Li-ion conductivity of the specimen, $\sigma_{\mathrm{t}}\left(\mathrm{S} \mathrm{cm}^{-1}\right)$, was achieved by the total resistance normalized with respect to the thickness and cross-sectional area of the specimen. The ionic conductivities of the undoped and multi-doped LLZO samples were calculated from Equation 2:

$$
\sigma_{t}=\frac{d}{A} \frac{1}{R}
$$

where $d, A$, and $R$ denote the thickness of the electrolyte, the cross-sectional area of the electrode, and the ionic resistance of the specimen, respectively. The total conductivities of the undoped and multi-doped LLZO samples at room temperature are presented in Table 1. The total conductivity $\left(\sigma_{\mathrm{t}}=2.4 \times 10^{-4} \mathrm{~S} \mathrm{~cm}^{-1}\right.$ at room temperature) of the undoped LLZO well agreed with reported values. Compared with the undoped LLZO, Liion conductivity clearly increased with increased doping of aliovalent ions into LLZO. The increase in total conductivity with increase multi-ion doping in the garnet framework can be well explained by the dense microstructure, decreased $96 h_{\mathrm{Li} 2} / 24 d_{\mathrm{Li} 1}$ ratio, and reduced oxygen occupancy in the multi-doped LLZO samples (Fig. 5). In the cubic polymorph, the $\mathrm{Li}^{+}$ions were partially occupied in the tetrahedral-24d $d_{\mathrm{Li} 1}$ and octahedral- 
$96 h_{\mathrm{Li} 2}$ sites, and the amount of distribution among each site greatly affected the Li-ion conductivity in LLZO.

The Li-ion conductivity of the LLZO cubic garnet depends on various key factors, such as (i) mobile $\mathrm{Li}^{+}$concentration, (ii) $\mathrm{Li}^{+}$vacancy $\left(V_{L i}\right)$ concentration, (iii) bottleneck size for $\mathrm{Li}^{+}$migration, (iv) Coulombic repulsion between $\mathrm{Li}^{+}-\mathrm{Li}^{+}$pair, and (v) specimen microstructure. ${ }^{40,}{ }^{45-49}$ It is well known that the nominal cubic garnet-type structure, $\mathrm{Li}_{7} \mathrm{La}_{3} \mathrm{Zr}_{2} \mathrm{O}_{12}$ is not stable at room temperature due the high Coulombic repulsion between $\mathrm{Li}^{+}-\mathrm{Li}^{+}$pair. ${ }^{50}$ In the mono-doped LLZTO, the substitution of high valence of $\mathrm{Ta}^{5+}$ for $\mathrm{Zr}^{4+}$ led to $\mathrm{Li}^{+}$vacancies and reduced $\mathrm{Li}^{+}$concentration for charge compensation, which promoted the $\mathrm{Li}^{+}$motion in the LLZTO framework. The substitution of $\mathrm{Ta}^{5+}$ for $\mathrm{Zr}^{4+}$ reduced the Coulombic repulsion between $\mathrm{Li}^{+}-\mathrm{Li}^{+}$pair by creating $\mathrm{Li}^{+}$vacancies. As a result, the mono-doped LLZTO showed conductivity higher than that of the undoped LLZO. Although $V_{L i}$ can promote ionic conductivity, there should be an optimal $V_{L i}$. The excess increment of $V_{L i}$ may result in reduced mobile $\mathrm{Li}^{+}$concentration in the garnet framework, which might reflect in low conductivities. Dual substation strategy can improve the $\mathrm{Li}^{+}$dynamics in Sb-Ba co-doped LLZO. ${ }^{51}$ In the dual-doped LLBZTO, the substitution of $\mathrm{Ta}^{5+}$ for $\mathrm{Zr}^{4+}$ and $\mathrm{Ba}^{2+}$ for $\mathrm{La}^{3+}$ may lead to optimal $\mathrm{Li}^{+}$concentration. Furthermore, the larger ionic radius $r$ of $\mathrm{Ba}^{2+}$ than $\mathrm{La}^{3+}$ may cause lattice expansion, which enlarged the bottleneck size for $\mathrm{Li}^{+}$migration and thereby resulted in a conductivity higher than that of the undoped LLZO and mono-doped LLZTO.

The Li rearrangement took place between the tetrahedral- $24 d_{\mathrm{Li1}}$ and octahedral$96 h_{\mathrm{Li} 2}$ sites due to the electrostatic repulsion of either $\mathrm{Li}^{+}-\mathrm{Li}^{+}$pair or $\mathrm{Li}^{+}$-dopant ion pair in the LLZO framework. ${ }^{48}$ The strong electrostatic repulsion of $\mathrm{Li}^{+}$-dopant ion pair may 
affect the neighboring $\mathrm{Li}^{+}$site, which can lead to the high mobility of $\mathrm{Li}^{+}$. Therefore, the Coulombic interaction between $\mathrm{Li}^{+}$and dopant cation was a determining factor for $\mathrm{Li}$-ion conductivities. Strategic doping of ions at the Li site in the LLZO may create strong Coulombic repulsion between dopant ion and $\mathrm{Li}^{+}$, which can influence the mobility of $\mathrm{Li}^{+}$. In the ternary-doped LGLBZTO, the substitution of $\mathrm{Ta}^{5+}$ for $\mathrm{Zr}^{4+}, \mathrm{Ba}^{2+}$ for $\mathrm{La}^{3+}$, and immobile $\mathrm{Ga}^{3+}$ for $\mathrm{Li}^{+}$created a strong Coulombic repulsion at the $\mathrm{Li}$ site, added to the enlarged bottleneck size from Ba doping. Hence, we can expect a high conductivity for the ternary-doped LGLBZTO, attributed to the enhanced $\mathrm{Li}^{+}$mobility arising from the Coulombic repulsion between $\mathrm{Li}^{+}$ions and dopant $\mathrm{Ga}$ ion. With the increased amount of doped ions, the total conductivity linearly increased. The optimum total ionic conductivity $\left(\sigma_{t}\right)$ achieved for the ternary-doped LGLBZTO ( $\mathrm{Li}_{6.65} \mathrm{Ga}_{0.05} \mathrm{La}_{2.95} \mathrm{Ba}_{0.05} \mathrm{Zr}_{1.75} \mathrm{Ta}_{0.25} \mathrm{O}_{12}$ ) was 0.72 and $1.24 \mathrm{mS} \mathrm{cm}^{-1}$ at room temperature and $60^{\circ} \mathrm{C}$, respectively.

The Nyquist plot of a symmetric lithium cell with the configuration of $\mathrm{Li}|\mathrm{LGLBZTO}| \mathrm{Li}$ recorded at room temperature and $60^{\circ} \mathrm{C}$ (Fig. S6†). The symmetrical cell showed two depressed semicircles with an inclined line. The first semicircle at highfrequencies shows a bulk resistance $\left(\mathrm{R}_{1}+\mathrm{R}_{2}\right)$ of $\sim 203 \Omega$ and $\sim 140 \Omega$ at room temperature and $60{ }^{\circ} \mathrm{C}$, respectively, correspond to the solid electrolyte. The second depressed semicircle at middle frequencies attributed to the interfacial resistance $\left(\mathrm{R}_{3}\right)$ of $\sim 8551 \Omega$ and $\sim 1912 \Omega$ at room temperature and $60{ }^{\circ} \mathrm{C}$, respectively, between the solid electrolyte and Li electrode was observed. The decreased interfacial resistance at $60{ }^{\circ} \mathrm{C}$, would be attributed to the formation of better contact between the solid electrolyte and Li metals. 
The total ionic conductivity varies linearly with the inverse temperature; the activation energy $E_{a}$ can be extracted from the Arrhenius plots using the following equation:

$$
\sigma_{\text {total }}=\sigma_{0} e^{-E_{a} / K T}
$$

where $\sigma_{0}$ is the pre-exponential factor, $K$ is the Boltzmann's constant $\left(8.62 \times 10^{-5} \mathrm{eV}\right.$ $\mathrm{K}^{-1}$ ), and $T$ is the absolute temperature in Kelvin. The Arrhenius plots for the relation between the total ionic conductivity and the inverse temperatures were obtained in the temperature range of $20-90{ }^{\circ} \mathrm{C}$. The data are shown in Fig. $4 \mathrm{~b}$. The Arrhenius total conductivities of the undoped LLZO, mono-doped LLZTO, dual-doped LLBZTO, and ternary-doped LGLBZTO showed linearity, which confirmed the homogeneity in the structure. The $E_{a}$ was calculated by obtaining the slope of the fitted line. The minimum $E_{a}$ was $0.28 \mathrm{eV}$ for ternary-doped LGLBZTO. The activation energy ranged from $0.28 \mathrm{eV}$ to $0.34 \mathrm{eV}$

Solid-state magic angle spinning NMR (MAS NMR) studies were performed to elucidate the differences in the local structural features of garnet LLZO. The solid-state ${ }^{7} \mathrm{Li}$ MAS NMR spectra of the undoped LLZO, mono-doped LLZTO, dual-doped LLBZTO, and ternary-doped LGLBZTO were recorded at room temperature (Fig. 6). All investigated garnet compounds showed a single central transition at $1.5 \mathrm{ppm}$ due to the $-1 / 2 \leftrightarrow 1 / 2$ transition along with other three satellite peaks $(-5 / 2 \leftrightarrow 5 / 2,-3 / 2 \leftrightarrow 3 / 2$, and $-1 / 2 \leftrightarrow 1 / 2$ transitions) corresponding to the spinning sidebands. The ${ }^{7} \mathrm{Li}$ MAS NMR results are consistent with the reported garnet-type compounds in literature. ${ }^{52,}{ }^{53}$ The central transition peak of the undoped LLZO at $1.7 \mathrm{ppm}$ slightly shifted to the shielded region in the multi-doped LLZOs with an increased amount of doped ions (Fig. 6a inset). 
In general, the full width at half-maximum (FWHM) of the central ${ }^{7} \mathrm{Li}$ transition was governed by the strength of homonuclear $\left({ }^{7} \mathrm{Li}{ }^{7} \mathrm{Li}\right)$ dipole-dipole interactions and $\mathrm{Li}^{+}$ migration ability. ${ }^{54}$ Fig. $6 \mathrm{~b}$ shows an apparent decrease in the FWHM of the ${ }^{7} \mathrm{Li}$ MAS NMR spectra with multi-ion doping in the LLZO framework. The narrow line width of the central transition was observed for the ternary-doped LGLBZTO, indicating weak homonuclear $\left({ }^{7} \mathrm{Li}-{ }^{7} \mathrm{Li}\right)$ dipole-dipole interactions that may be attributed to the increased $\mathrm{Li}^{+}$migration ability. However, spin-lattice relaxation times $\left(T_{1}\right)$ could give further insight into the diffusion behavior of $\mathrm{Li}$ in LLZO garnet. The systematic variable temperature NMR studies are required to understand the $\mathrm{Li}^{+}$dynamics and their coordination geometry in the undoped and multi-doped LLZO samples. ${ }^{55}$

${ }^{71} \mathrm{Ga}$ (spin quantum number, $I=3 / 2$ ) MAS NMR measurement was carried out to evaluate the crystallographic site and symmetry of the Ga environment in the garnet structure. The ${ }^{71}$ Ga MAS NMR spectrum of the ternary-doped LGLBZTO powder recorded at room temperature is shown in Fig. 6c. The sample showed one broad signal in the range of $210-255 \mathrm{ppm}$ in the ${ }^{71} \mathrm{Ga}$ MAS spectrum, indicating that the $\mathrm{Ga}$ ions in ternary-doped LGLBZTO were located in a single structural site (tetrahedral coordination $\mathrm{Li}_{24 d}$ site). Furthermore, NPD results confirmed the site occupancy for Ga (vide infra). The small peaks at around 170 and $300 \mathrm{ppm}$ were the spinning sidebands. The signal at 107-222 ppm corresponded to the tetrahedral environment. ${ }^{56,57}$ In an octahedral environment, the Ga signal appeared in up field shift within 80 and $-42 \mathrm{ppm} .{ }^{56-58}$

NPD, which offers high sensitivity to light elements (e.g., Li and O) at the presence of heavy elements, was carried out to investigate the influence of doping aliovalent ions $\mathrm{Ga}^{3+}, \mathrm{Ba}^{2+}$, and $\mathrm{Ta}^{5+}$ at the $\mathrm{Li}^{+}, \mathrm{La}^{3+}$, and $\mathrm{Zr}^{4+}$ sites, respectively, on the $\mathrm{Li}^{+}$distribution in 
the garnet structure LLZO. Room temperature NPD data were collected for the undoped LLZO, mono-doped LLZTO, dual-doped LLBZTO, and ternary-doped LGLBZTO powders calcined at $900{ }^{\circ} \mathrm{C}$ for $12 \mathrm{~h}$. Fig. 7 displays the corresponding Rietveld refinement plots. The refined structural parameters are summarized in Table 2. The Rietveld refinements were analyzed using the general structure analysis system (GSASII). The $\mathrm{La}^{3+}, \mathrm{Zr}^{4+}$, and $\mathrm{O}^{2-}$ in the garnet structure were considered to occupy the dodecahedral $24 c$, octahedral $16 a$, and octahedral $96 h$ sites, respectively. The $\mathrm{Li}^{+}$ions were located on two sites: tetrahedral-24d $d_{\mathrm{Li} 1}$ and distorted octahedral-96h $h_{\mathrm{Li} 2} . \mathrm{Ba}^{2+}$ and $\mathrm{Ta}^{5+}$ were partially substituted at the similar ionic radii of dodecahedral $24 c\left(\mathrm{La}^{3+}\right)$ and octahedral $16 a\left(\mathrm{Zr}^{4+}\right)$ sites, respectively, without blocking the $\mathrm{Li}^{+}$transport path in the garnet framework. ${ }^{59}$ NPD measurements confirmed that $\mathrm{Ga}^{3+}$ was preferentially located at the tetrahedral-24d $d_{\mathrm{Li} 1}(r=0.59 \AA)$ site rather than the octahedral-96h $h_{\mathrm{Li} 2}(r=0.76 \AA)$ site due to the small ionic radius of $\mathrm{Ga}^{3+}\left(r=0.47 \AA\right.$ in a tetrahedral coordination). ${ }^{22,40,60 \text {, }}$ ${ }^{61}$ The slightly large lattice parameters in the dual-doped LLBZTO and ternary-doped LGLBZTO can be explained by the substitution of larger doping ionic radius of $\mathrm{Ba}^{2+}(r=$ $1.42 \AA$ in VIII co-ordination) for the smaller $\mathrm{La}^{3+}(r=1.16 \AA$ in VIII coordination) in the LLZO system. The reduced lattice constant observed for the mono-doped LLZTO was due to the smaller doping ionic radius of $\mathrm{Ta}^{5+}\left(r=0.64 \AA\right.$ in VI coordination) over $\mathrm{Zr}^{4+}(r$ $=0.72 \AA$ in VI coordination). ${ }^{62}$ The refined lattice parameters, Li occupancy at the tetrahedral-24d $d_{\mathrm{Li} 1}$ and octahedral-96h $h_{\mathrm{Li} 2}$ sites, the ratio of octahedral-96h $h_{\mathrm{Li} 2}$ to tetrahedral$24 d_{\mathrm{Li} 1}, \mathrm{O}^{2-}$ occupancy at the $96 \mathrm{~h}$ site, and unit-cell volumes of the undoped and multidoped LLZOs are presented in Table 3. The supervalent cation substitution, either $\mathrm{Ta}^{5+}$ at the $\mathrm{Zr}^{4+}$ site or $\mathrm{Ga}^{3+}$ at the $\mathrm{Li}^{+}$site, leads to the stabilization of high-conducting cubic 
polymorph. In our NPD refinement, the occupancy of $\mathrm{Li}$ at the tetrahedral-24d $d_{\mathrm{Li} 1}$ site increased with increased number of doped ions, whereas the Li occupancy at the octahedral-96h $h_{\mathrm{Li} 2}$ remained constant. In the undoped LLZO, the lithium ions reside equally at octahedral-96h $h_{\mathrm{Li} 2}(0.36(5))$ and tetrahedral-24d $d_{\mathrm{L} 11}(0.35(3))$ sites. Upon multidoping elements, increase of $\mathrm{Li}$ occupation at the tetrahedral-24d $d_{\mathrm{Li} 1}$ site was observed. The occupancy of lithium in the tetrahedral-24d $d_{\mathrm{Li}}$ sites increased from $0.36(5)$ to $0.77(5)$ with ternary element doping. Thus, the tetrahedral-24d $d_{\mathrm{L} 11}$ :octahedral-96h $h_{\mathrm{Li} 2} \mathrm{Li}$ occupancy ratio increased with increased number of doped ions. It is generally believed that the immobile Al dopant in the garnet framework is occupied at Li sites may cause blocking the $\mathrm{Li}^{+}$transport in Al-doped LLZO garnets. ${ }^{20}$ Shin et al. reported that doping of tantalum into the Al-doped LLZO garnet, the blocking immobile Al shifts from tetrahedral-24d $d_{\mathrm{Li} 1}$ to octahedral-96h $h_{\mathrm{Li} 2}$ site, thereby providing more open space for $\mathrm{Li}$ ion transport. ${ }^{63} \mathrm{We}$ believe that multi-ion doping into the garnet framework caused structural alteration and provides more space in tetrahedral-24d $d_{\mathrm{Li1}}$ site. The lithium ion mobility at the tetrahedral$24 d_{\text {Li1 }}$ sites plays an important role for the total ionic conductivity in garnet-type structures. ${ }^{64,65}$ Additionally, a reduction in oxygen defects with an increased amount of doped ions was observed from the Rietveld analysis. The decrease in oxygen occupancy created a positive hole for $\mathrm{Li}^{+}$hopping. Wu, J.-F. et al. ${ }^{40,61}$, Rettenwander, D. et al. ${ }^{66}$ and Jalem, R. et al ${ }^{65}$ reported that the electrochemical properties improved with increased Li occupancy at the tetrahedral-24d $d_{\text {Li1 }}$ site, which can serve as the trigger for Li-ion mobility in LLZO garnet-type systems. Recently, we found that the increased Li content along with the reduced oxygen defects can enhance the Li-ion conductivity in Al-doped LLZO by locally rearranging the oxygen atoms in the anionic framework during voltammetric 
treatment. ${ }^{67}$ The increased ionic conductivity with multi-ion doping can be ascribed to the partial occupancy of $\mathrm{Li}^{+}$across the tetrahedral-24d $d_{\mathrm{Li} 1}$ and octahedral-96h $h_{\mathrm{L} 2}$ sites, decreased Li occupancy ratio ( $\left.96 h_{\mathrm{Li} 2} / 24 d_{\mathrm{Li} 1}\right)$, and reduced oxygen defects.

The viability of the garnet solid electrolyte for the all-solid-state battery was demonstrated by constructing a half-cell with $\mathrm{Li}$ metal, $\mathrm{Li}_{6.65} \mathrm{Ga}_{0.05} \mathrm{La}_{2.95} \mathrm{Ba}_{0.05} \mathrm{Zr}_{1.75} \mathrm{Ta}_{0.25} \mathrm{O}_{12}$ (ternary-doped LGLBZTO), and $\mathrm{LiFePO}_{4}$ as the active electrodes. To reduce the interfacial resistance between electrolyte and cathode, bis-trifluoromethane sulfonamide Li salt was added into the cathode material. Fig. 8 shows the cycle performance of the half-cell with ternary-doped LGLBZTO electrolyte, metallic $\mathrm{Li}$ anode, and $\mathrm{LiFePO}_{4}$ cathode. AC impedance measurements were conducted for the half-cells before and after $5^{\text {th }}$ lithiation/delithiation at $60{ }^{\circ} \mathrm{C}$ to evaluate the cell resistance evolution (Fig. S7†). In all cases, two depressed semicircles were observed at high and middle frequencies, followed by an inclined line at lower frequency. The high/middle frequency behavior was attributed to the interfacial resistances between electrolyte and electrodes. ${ }^{68}$ After $5^{\text {th }}$ cycle, the interfacial resistances for the half cells with undoped LLZO and multi-doped LLZOs are mildly increased. However, the increment in interfacial resistance between the electrolyte and electrodes decreased obviously with multi-ion doping. Galvanostatic charge-discharge curves were achieved within the cut off voltage range of 2.7-3.8 $\mathrm{V}_{\text {against }} \mathrm{Li}^{+} / \mathrm{Li}$ at $0.05 \mathrm{C}\left(1 \mathrm{C}=170 \mathrm{mAh} \mathrm{g}^{-1}\right)$ and $60{ }^{\circ} \mathrm{C}$ (Fig. 8a). The first charge and discharge capacities of $160.0 \mathrm{mAh} \mathrm{g}^{-1}$ and $146.8 \mathrm{mAh} \mathrm{g}^{-1}$, which corresponded to approximately $94.1 \%$ and $86.4 \%$ of the theoretical capacity $\left(170 \mathrm{mAh} \mathrm{g}^{-1}\right)$, respectively, at $0.05 \mathrm{C}$ were delivered.

The first Coulombic efficiency was 91.8\%, however the Coulombic efficiency was 
increased in the following cycles, and approximately $96.6 \%$ for the $6^{\text {th }}$ cycle as can be seen in Fig. 8b. The gradual increase in the cell overpotential and the decrease in the discharge capacity were due to the rigid nature of the solid electrolyte and poor contact with electrodes during the cycle. Optimizing the electrolyte/electrode interfaces using various buffer layer coating can solve such issue.

\section{Conclusions}

In summary, an efficient multi-doping strategy approached to enhance the Li-ion conductivity of garnet-type solid electrolyte $\mathrm{Li}_{7} \mathrm{La}_{3} \mathrm{Zr}_{2} \mathrm{O}_{12}$. We synthesized the undoped LLZO, mono-doped LLZTO, dual-doped LLBZTO, and ternary-doped LGLBZTO using the solid-state method. The synthesized garnet electrolytes were characterized via XRD, NPD, SEM, EDS mapping, and solid-state NMR techniques. The ceramic density of the synthesized garnets was near the theoretical density of LLZO. NPD Rietveld analysis revealed an increased $\mathrm{Li}^{+}$occupancy at the tetrahedral-24d $d_{\mathrm{Li} 1}$ site with increased multiion doping in LLZO, whereas $\mathrm{Li}^{+}$occupancy at the octahedral-96h $h_{\mathrm{Li} 2}$ site remained constant. The increased Li-ion conductivity with multi-ion doping can be ascribed to the dense microstructure, decreased $96 h_{\mathrm{Li} 2} / 24 d_{\mathrm{Li} 1} \mathrm{Li}^{+}$occupancy ratio, and reduced oxygen defects. The prepared ternary-doped LGLBZTO was tested for all solid-state $\mathrm{Li}^{+}$cells with Li|LGLBZTO|LFP configuration and results showed a reasonable cyclability of over 6 cycles.

\section{Supporting Information}


† Electronic supplementary information (ESI) available: Particle size distribution, microstructures, Rietveld refinement parameters, refined XRD spectra and impedance plots are included in the SI.

\section{Conflicts of interest}

The authors declare no competing financial interest.

\section{Acknowledgments}

This work was financially supported by the Ministry of Science and Technology of Taiwan (contract nos. MOST 107-2113-M-002-008-MY3 and MOST 106-2112-M-003007-MY3) and the Material and Chemical Research Laboratories, Industrial Technology

Research Institute, Hsinchu, Taiwan. W.K. Pang is grateful for the financial support of the Australian Research Council (ARC, FT160100251) and the University of Wollongong through the UIC International Links Grant Scheme 2018. The authors would also like to thank the staff members of the Australian Centre for Neutron Scattering, ANSTO for their operations support.

\section{References}

1 J. B. Goodenough and Y. Kim, Chem. Mater., 2010, 22, 587-603.

2 J. M. Tarascon and M. Armand, Nature, 2001, 414, 359-367.

3 E. J. Cheng, A. Sharafi and J. Sakamoto, Electrochim. Acta, 2017, 223, 85-91.

4 A. W. Golubkov, D. Fuchs, J. Wagner, H. Wiltsche, C. Stangl, G. Fauler, G. Voitic, A. Thaler and V. Hacker, RSC Adv., 2014, 4, 3633-3642.

$5 \quad$ P. Knauth, Solid State Ionics, 2009, 180, 911-916.

$6 \quad$ Y. Meesala, A. Jena, H. Chang and R.-S. Liu, ACS Energy Lett., 2017, 2, 27342751. 
7 Z. Zhang, Y. Shao, B. V. Lotsch, Y.-S. Hu, H. Li, J. Janek, C. Nan, L. Nazar, J. Maier and M. Armand, Energy Environ. Sci., 2018.

8 F. Zheng, M. Kotobuki, S. Song, M. O. Lai and L. Lu, J. Power Sources, 2018, 389, 198-213.

9 R. Murugan, V. Thangadurai and W. Weppner, Angew. Chem., Int. Ed., 2007, 46, 7778-7781.

10 C. Cao, Z.-B. Li, X.-L. Wang, X.-B. Zhao and W.-Q. Han, Front. Energy Res. , 2014, 2, 25.

11 Y. Zhu, X. He and Y. Mo, ACS Appl. Mater. Interfaces, 2015, 7, 23685-23693.

12 J. Awaka, N. Kijima, H. Hayakawa and J. Akimoto, J. Solid State Chem., 2009, 182, 2046-2052.

13 J. Awaka, A. Takashima, K. Kataoka, N. Kijima, Y. Idemoto and J. Akimoto, Chem. Lett., 2011, 40, 60-62.

14 H. Buschmann, J. Dölle, S. Berendts, A. Kuhn, P. Bottke, M. Wilkening, P. Heitjans, A. Senyshyn, H. Ehrenberg and A. Lotnyk, Phys. Chem. Chem. Phys., 2011, 13, 19378-19392.

15 V. Thangadurai, S. Narayanan and D. Pinzaru, Chem. Soc. Rev., 2014, 43, 47144727.

16 C. A. Geiger, E. Alekseev, B. Lazic, M. Fisch, T. Armbruster, R. Langner, M. Fechtelkord, N. Kim, T. Pettke and W. Weppner, Inorg. Chem., 2011, 50, 10891097.

17 S. Kumazaki, Y. Iriyama, K.-H. Kim, R. Murugan, K. Tanabe, K. Yamamoto, T. Hirayama and Z. Ogumi, Electrochem. Commun., 2011, 13, 509-512.

18 M. Kotobuki, K. Kanamura, Y. Sato and T. Yoshida, J. Power Sources, 2011, 196, $7750-7754$.

19 E. Rangasamy, J. Wolfenstine and J. Sakamoto, Solid State Ionics, 2012, 206, 2832.

20 D. Rettenwander, P. Blaha, R. Laskowski, K. Schwarz, P. Bottke, M. Wilkening, C. A. Geiger and G. Amthauer, Chem. Mater., 2014, 26, 2617-2623.

21 N. Bernstein, M. Johannes and K. Hoang, Phys. Rev. Lett., 2012, 109, 205702.

22 C. Bernuy-Lopez, W. Manalastas Jr, J. M. Lopez del Amo, A. Aguadero, F. Aguesse and J. A. Kilner, Chem. Mater., 2014, 26, 3610-3617.

23 R. Jalem, M. Rushton, W. Manalastas Jr, M. Nakayama, T. Kasuga, J. A. Kilner and R. W. Grimes, Chem. Mater., 2015, 27, 2821-2831.

24 S. Song, B. Yan, F. Zheng, H. M. Duong and L. Lu, Solid State Ionics, 2014, 268, 135-139.

25 J. L. Allen, J. Wolfenstine, E. Rangasamy and J. Sakamoto, J. Power Sources, 2012, 206, 315-319. 
26 S. Ohta, T. Kobayashi and T. Asaoka, J. Power Sources, 2011, 196, 3342-3345.

27 S. Ramakumar, L. Satyanarayana, S. V. Manorama and R. Murugan, Phys.Chem. Chem. Phys., 2013, 15, 11327-11338.

28 T. Yang, Y. Li, W. Wu, Z. Cao, W. He, Y. Gao, J. Liu and G. Li, Ceram. Int., 2018, 44, 1538-1544.

29 R. Wagner, D. Rettenwander, G. n. J. Redhammer, G. Tippelt, G. Sabathi, M. E. Musso, B. Stanje, M. Wilkening, E. Suard and G. Amthauer, Inorg. Chem., 2016, 55, 12211-12219.

30 V. Thangadurai and W. Weppner, J. Am. Ceram. Soc., 2005, 88, 411-418.

31 A. Dumon, M. Huang, Y. Shen and C.-W. Nan, Solid State Ionics, 2013, 243, 3641.

32 W. Bucheli, T. Durán, R. Jimenez, J. s. Sanz and A. Varez, Inorg. Chem. , 2012, 51, 5831-5838.

33 L. Buannic, B. Orayech, J.-M. López Del Amo, J. Carrasco, N. A. Katcho, F. d. r. Aguesse, W. Manalastas, W. Zhang, J. Kilner and A. Llordés, Chem. Mater., 2017, 29, 1769-1778.

34 F. Du, N. Zhao, Y. Li, C. Chen, Z. Liu and X. Guo, J. Power Sources, 2015, 300, 24-28.

35 S. Rajendran, M. S. Song, M. S. Park, J. H. Kim and J. Y. Lee, Mater. Lett., 2005, 59, 2347-2351.

36 H. Hyooma and K. Hayashi, Mat. Res. Bull., 1988, 23, 1399-1407.

37 F. Tietz, T. Wegener, M. Gerhards, M. Giarola and G. Mariotto, Solid State Ionics, 2013, 230, 77-82.

38 G. Larraz, A. Orera and M. Sanjuan, J. Mater. Chem. A, 2013, 1, 11419-11428.

39 T. Thompson, J. Wolfenstine, J. L. Allen, M. Johannes, A. Huq, I. N. David and J. Sakamoto, J. Mater. Chem. A, 2014, 2, 13431-13436.

40 J.-F. Wu, E.-Y. Chen, Y. Yu, L. Liu, Y. Wu, W. K. Pang, V. K. Peterson and X. Guo, ACS Appl. Mater. Interfaces, 2017, 9, 1542-1552.

41 Y. Li, X. Chen, A. Dolocan, Z. Cui, S. Xin, L. Xue, H. Xu, K. Park and J. B. Goodenough, J. Am. Chem. Soc., 2018, 140, 6448-6455.

42 F. Shen, M. B. Dixit, X. Xiao and K. B. Hatzell, ACS Energy Lett., 2018, 3, 10561061.

43 L. Cheng, W. Chen, M. Kunz, K. Persson, N. Tamura, G. Chen and M. Doeff, ACS Appl. Mater. Interfaces, 2015, 7, 2073-2081.

44 C.-L. Tsai, V. Roddatis, C. V. Chandran, Q. Ma, S. Uhlenbruck, M. Bram, P. Heitjans and O. Guillon, ACS Appl. Mater. Interfaces, 2016, 8, 10617-10626.

45 W. G. Zeier, Dalton Trans., 2014, 43, 16133-16138. 
46 L. J. Miara, S. P. Ong, Y. Mo, W. D. Richards, Y. Park, J.-M. Lee, H. S. Lee and G. Ceder, Chem. Mater., 2013, 25, 3048-3055.

47 J. C. Bachman, S. Muy, A. Grimaud, H.-H. Chang, N. Pour, S. F. Lux, O. Paschos, F. Maglia, S. Lupart, P. Lamp, L. Giordano and S.-H. Yang, Chem. Rev., 2016, 116, 140-162.

48 Y. Chen, E. Rangasamy, C. Liang and K. An, Chem. Mater. , 2015, 27, 54915494.

49 Y. Zhang, J. Deng, D. Hu, F. Chen, Q. Shen, L. Zhang and S. Dong, Electrochim. Acta, 2019, 296, 823-829.

50 M. Xu, M. S. Park, J. M. Lee, T. Y. Kim, Y. S. Park and E. Ma, Phys. Rev. B, 2012, 85, 052301.

51 Z. Cao, X. Cao, X. Liu, W. He, Y. Gao, J. Liu and J. Zeng, Ceram. Int., 2015, 41, 6232-6236.

52 L. van Wüllen, T. Echelmeyer, H.-W. Meyer and D. Wilmer, Phys. Chem. Chem. Phys., 2007, 9, 3298-3303.

53 M. P. O’Callaghan, A. S. Powell, J. J. Titman, G. Z. Chen and E. J. Cussen, Chem. Mater., 2008, 20, 2360-2369.

54 M. Forsyth, S. Wong, K. Nairn, A. Best, P. Newman and D. MacFarlane, Solid State Ionics, 1999, 124, 213-219.

55 A. Kuhn, M. Kunze, P. Sreeraj, H.-D. Wiemhöfer, V. Thangadurai, M. Wilkening and P. Heitjans, Solid State Nucl. Magn. Reson., 2012, 42, 2-8.

56 J. T. Ash and P. J. Grandinetti, Magn. Reson. Chem., 2006, 44, 823-831.

57 F. Blanc, D. S. Middlemiss, Z. Gan and C. P. Grey, J. Am. Chem. Soc., 2011, 133, 17662-17672.

58 D. Massiot, T. Vosegaard, N. Magneron, D. Trumeau, V. Montouillout, P. Berthet, T. Loiseau and B. Bujoli, Solid State Nucl. Magn. Reson., 1999, 15, 159169.

59 R. Inada, S. Yasuda, M. Tojo, K. Tsuritani, T. Tojo and Y. Sakurai, Front. Energy Res., 2016, 4, 28.

60 M. Howard, O. Clemens, E. Kendrick, K. Knight, D. Apperley, P. Anderson and P. Slater, Dalton Trans., 2012, 41, 12048-12053.

61 J.-F. Wu, W. K. Pang, V. K. Peterson, L. Wei and X. Guo, ACS Appl. Mater. Interfaces, 2017, 9, 12461-12468.

62 R. D. Shannon, Acta Cryst. A, 1976, A32, 751-767.

63 D. O. Shin, K. Oh, K. M. Kim, K.-Y. Park, B. Lee, Y.-G. Lee and K. Kang, Sci. Rep., 2015, 5, 18053.

64 D. Wang, G. Zhong, W. K. Pang, Z. Guo, Y. Li, M. J. McDonald, R. Fu, J.-X. Mi and Y. Yang, Chem. Mater., 2015, 27, 6650-6659. 
65 R. Jalem, Y. Yamamoto, H. Shiiba, M. Nakayama, H. Munakata, T. Kasuga and K. Kanamura, Chem. Mater., 2013, 25, 425-430.

66 D. Rettenwander, G. n. Redhammer, F. Preishuber-Pflügl, L. Cheng, L. Miara, R. Wagner, A. Welzl, E. Suard, M. M. Doeff and M. Wilkening, Chem. Mater., 2016, 28, 2384-2392.

67 Y.-T. Chen, A. Jena, W. K. Pang, V. K. Peterson, H.-S. Sheu, H. Chang and R.-S. Liu, J. Phys. Chem. C, 2017, 121, 15565-15573.

68 Y. Meesala, C.-Y. Chen, A. Jena, Y.-K. Liao, S.-F. Hu, H. Chang and R.-S. Liu, J. Phys. Chem. C, 2018, 122, 14383-14389. 


\section{Legends:}

Table 1. Density $\left(\mathrm{g} / \mathrm{cm}^{3}\right)$, ceramic density (\%), total ionic conductivity, and activation energy of the undoped LLZO, mono-doped LLZTO, dual-doped LLBZTO, and ternarydoped LGLBZTO.

Table 2. Structural parameters of the undoped LLZO, mono-doped LLZTO, dual-doped LLBZTO, and ternary-doped LGLBZTO obtained using NPD (space group $I a \overline{3} d$ ).

Table 3. Refined lattice parameters, unit-cell volumes, Li occupancy at the tetrahedral$24 d_{\mathrm{Li} 1}$ and octahedral-96h $h_{\mathrm{Li} 2}$ sites, the ratio of octahedral-96h $h_{\mathrm{Li} 2}:$ tetrahedral-24d $d_{\mathrm{Li} 1}$, and $\mathrm{O}^{2-}$ occupancy at the $96 \mathrm{~h}$ site of the undoped LLZO, mono-doped LLZTO, dual-doped LLBZTO, and ternary-doped LGLBZTO.

Fig. 1 (a) XRD patterns and (b) peak shift of the undoped LLZO, mono-doped LLZTO, dual-doped LLBZTO, and ternary-doped LGLBZTO in the range of $25^{\circ}-32^{\circ}$ (c) Crystal structure of cubic LLZO with connectivity pattern of tetrahedral-24d $d_{\mathrm{Li} 1}$ and $96 h_{\mathrm{Li} 2}$ cages projected on two dimensions.

Fig. 2 Raman spectra of the undoped LLZO, mono-doped LLZTO, dual-doped LLBZTO, and ternary-doped LGLBZTO in the range of $50-800 \mathrm{~cm}^{-1}$.

Fig. 3 SEM image and corresponding EDX maps of La, Zr, Al, Ta, Ba, and Ga for (a) undoped LLZO, (b) mono-doped LLZTO, (c) dual-doped LLBZTO, and (d) ternarydoped LGLBZTO.

Fig. 4 (a) AC impedance plot of the garnet-type ternary-doped LGLBZTO $\mathrm{Li}_{6.65} \mathrm{Ga}_{0.05} \mathrm{La}_{2.95} \mathrm{Ba}_{0.05} \mathrm{Zr}_{1.75} \mathrm{Ta}_{0.25} \mathrm{O}_{12}$. Inset is the equivalent circuit used to fit the curve. (b) Arrhenius plot of the undoped LLZO, mono-doped LLZTO, dual-doped LLBZTO, and ternary-doped LGLBZTO. 
Fig. 5 Comparison plot for (a) density and total ionic conductivity at room temperature and $\mathrm{Li}$ occupancy ratio at $96 h_{\mathrm{Li} 2} / 24 d_{\mathrm{Li} 1}$. (b) $\mathrm{O}^{2-}$ occupancy with lattice parameters of the undoped LLZO, mono-doped LLZTO, dual-doped LLBZTO, and ternary-doped LGLBZTO. The total ionic conductivity and density increases, whereas the Li occupancy ration at $96 h_{\mathrm{Li} 2} / 24 d_{\mathrm{Li} 1}$ decreases with multi-ion doping into the garnet.

Fig. 6 (a) ${ }^{7}$ Li MAS NMR (b) FWHM of the central transition line width in the undoped LLZO, mono-doped LLZTO, dual-doped LLBZTO, and ternary-doped LGLBZTO. The inset shows the magnified scale (*spinning sidebands). (c) ${ }^{71} \mathrm{Ga}$ NMR spectrum for the ternary-doped LGLBZTO showing a single broad signal at 210-255 ppm. The weak signals correspond to the spinning sidebands.

Fig. 7 Rietveld refined NPD pattern for the (a) undoped LLZO, (b) mono-doped LLZTO, (c) dual-doped LLBZTO, and (d) ternary-doped LGLBZTO. observed (crosses), calculated, and difference profiles; Vertical bars correspond to the calculated Bragg reflections for cubic garnet.

Fig. 8 (a) Galvanostatic charge-discharge curves of the LFP/LGLBZTO/Li structured cell at $0.05 \mathrm{C}$ and $60^{\circ} \mathrm{C}$. (b) Capacity retention of cell LFP/LGLBZTO/Li at $0.05 \mathrm{C}$ after 6 cycles. 
Table 1

\begin{tabular}{lllll}
\hline Garnet & density $\left(\mathrm{g} / \mathrm{cm}^{3}\right)$ & ceramic density $(\%)$ & $\sigma_{\text {total }}\left(\mathrm{S} \mathrm{cm}^{-1}\right)$ & $E_{a}(\mathrm{eV})$ \\
\hline LLZO & 4.939 & 96.7 & $2.4 \times 10^{-4}$ & 0.34 \\
LLZTO & 5.086 & 99.6 & $4.3 \times 10^{-4}$ & 0.32 \\
LLBZTO & 5.091 & 99.7 & $6.5 \times 10^{-4}$ & 0.29 \\
LGLBZTO & 5.137 & 99.9 & $7.2 \times 10^{-4}$ & 0.28 \\
\hline
\end{tabular}


Table 2

\begin{tabular}{|c|c|c|c|c|c|c|c|c|c|}
\hline Garnet & L.P./Å & GOF & $\boldsymbol{R}_{w p}$ & site & occupancy & $x$ & $y$ & $\mathbf{Z}$ & $U_{\text {iso }}\left(\AA^{2}\right)$ \\
\hline LLZO & $12.9773(2)$ & 1.97 & $7.11 \%$ & $\begin{array}{l}\mathrm{Li}(24 d) \\
\mathrm{Li}(96 h) \\
\mathrm{Al}(24 d) \\
\mathrm{La}(24 c) \\
\mathrm{Zr}(16 a) \\
\mathrm{O}(96 h)\end{array}$ & $\begin{array}{l}0.32(4) \\
0.36(2) \\
0.06 \\
0.96(2) \\
0.99(3) \\
0.97(1)\end{array}$ & $\begin{array}{l}3 / 8 \\
0.690(2) \\
3 / 8 \\
1 / 8 \\
0 \\
0.099(1)\end{array}$ & $\begin{array}{l}0 \\
0.578(2) \\
0 \\
0 \\
0 \\
0.194(6)\end{array}$ & $\begin{array}{l}1 / 4 \\
0.094(2) \\
1 / 4 \\
1 / 4 \\
0 \\
0.280(5)\end{array}$ & $\begin{array}{l}0.003(1) \\
0.003(1) \\
0.01 \\
0.054(4) \\
0.048(4) \\
0.051(2)\end{array}$ \\
\hline LLZTO & $12.9629(2)$ & 2.21 & $3.59 \%$ & $\begin{array}{l}\operatorname{Li}(24 d) \\
\operatorname{Li}(96 h) \\
\operatorname{La}(24 c) \\
\operatorname{Zr}(16 a) \\
\operatorname{Ta}(16 a) \\
\mathrm{O}(96 h)\end{array}$ & $\begin{array}{l}0.52(4) \\
0.33(2) \\
0.96(9) \\
0.86(8) \\
0.11(8) \\
0.95(6)\end{array}$ & $\begin{array}{l}3 / 8 \\
0.692(2) \\
1 / 8 \\
0 \\
0 \\
0.101(2)\end{array}$ & $\begin{array}{l}0 \\
0.600(1) \\
0 \\
0 \\
0 \\
0.194(2)\end{array}$ & $\begin{array}{l}1 / 4 \\
0.098(2) \\
1 / 4 \\
0 \\
0 \\
0.280(2)\end{array}$ & $\begin{array}{l}0.066(1) \\
0.066(1) \\
0.026(1) \\
0.032(2) \\
0.032(2) \\
0.026(9)\end{array}$ \\
\hline LLBZTO & $13.0186(6)$ & 2.14 & $2.09 \%$ & $\begin{array}{l}\mathrm{Li}(24 d) \\
\mathrm{Li}(96 h) \\
\mathrm{La}(24 c) \\
\mathrm{Ba}(24 c) \\
\operatorname{Zr}(16 a) \\
\mathrm{Ta}(16 a) \\
\mathrm{O}(96 h)\end{array}$ & $\begin{array}{l}0.65(8) \\
0.33(2) \\
0.95(6) \\
0.07(1) \\
0.85(1) \\
0.15(1) \\
0.84(8)\end{array}$ & $\begin{array}{l}3 / 8 \\
0.697(3) \\
1 / 8 \\
1 / 8 \\
0 \\
0 \\
0.101(4)\end{array}$ & $\begin{array}{l}0 \\
0.585(3) \\
0 \\
0 \\
0 \\
0 \\
0.194(4)\end{array}$ & $\begin{array}{l}1 / 4 \\
0.131(4) \\
1 / 4 \\
1 / 4 \\
0 \\
0 \\
0.278(3)\end{array}$ & $\begin{array}{l}0.100(3) \\
0.066(1) \\
0.035(2) \\
0.035(2) \\
0.072(4) \\
0.072(4) \\
0.027(1)\end{array}$ \\
\hline LGLBZTO & $13.03858(1)$ & 2.16 & $2.61 \%$ & $\begin{array}{l}\mathrm{Li}(24 d) \\
\mathrm{Li}(96 h) \\
\mathrm{Ga}(24 d) \\
\mathrm{La}(24 c) \\
\mathrm{Ba}(24 c) \\
\mathrm{Zr}(16 a) \\
\mathrm{Ta}(16 a) \\
\mathrm{O}(96 h)\end{array}$ & $\begin{array}{l}0.77(5) \\
0.33(3) \\
0.04(6) \\
0.95(5) \\
0.04(9) \\
0.86(1) \\
0.14(1) \\
0.76(6)\end{array}$ & $\begin{array}{l}3 / 8 \\
0.698(4) \\
3 / 8 \\
1 / 8 \\
1 / 8 \\
0 \\
0 \\
0.101(4)\end{array}$ & $\begin{array}{l}0 \\
0.595(3) \\
0 \\
0 \\
0 \\
0 \\
0 \\
0.194(4)\end{array}$ & $\begin{array}{l}1 / 4 \\
0.211(4) \\
1 / 4 \\
1 / 4 \\
1 / 4 \\
0 \\
0 \\
0.278(3)\end{array}$ & $\begin{array}{l}0.040(7) \\
0.040(7) \\
0.040(7) \\
0.017(1) \\
0.017(1) \\
0.033(1) \\
0.033(1) \\
0.014(9)\end{array}$ \\
\hline
\end{tabular}


Table 3

\begin{tabular}{lllll}
\hline Garnet & LLZO & LLZTO & LLBZTO & LGLBZTO \\
\hline${ }^{a} L . P . / \AA$ & $12.9773(2)$ & $12.9629(2)$ & $13.0186(6)$ & $13.03858(1)$ \\
${ }^{b} V / \AA^{3}$ & $2178.7(1)$ & $2178.2(8)$ & $2207.3(3)$ & $2216.4(3)$ \\
$24 d_{L i 1}$ & $0.36(5)$ & $0.52(4)$ & $0.65(8)$ & $0.77(5)$ \\
$96 h_{L i 2}$ & $0.35(3)$ & $0.33(2)$ & $0.33(2)$ & $0.33(3)$ \\
$96 h_{L i 2} / 24 d_{L i 1}$ & 0.97 & 0.63 & 0.51 & 0.43 \\
$O^{2-}$ & $0.97(1)$ & $0.95(6)$ & $0.84(8)$ & $0.76(6)$ \\
\hline
\end{tabular}

${ }^{\mathrm{a}}$ Lattice parameter; ${ }^{\mathrm{b}}$ Volume 
Fig. 1

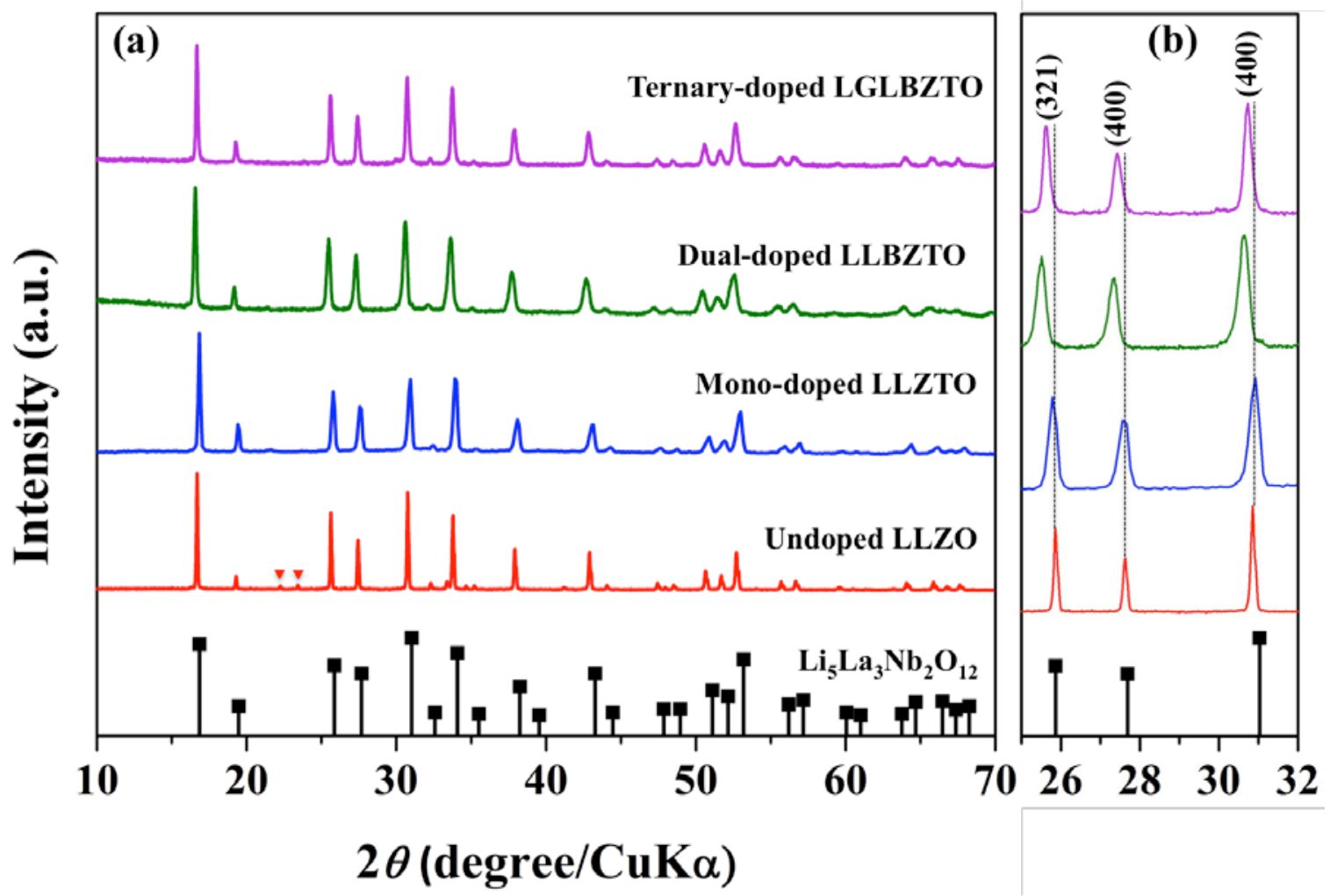

(c)
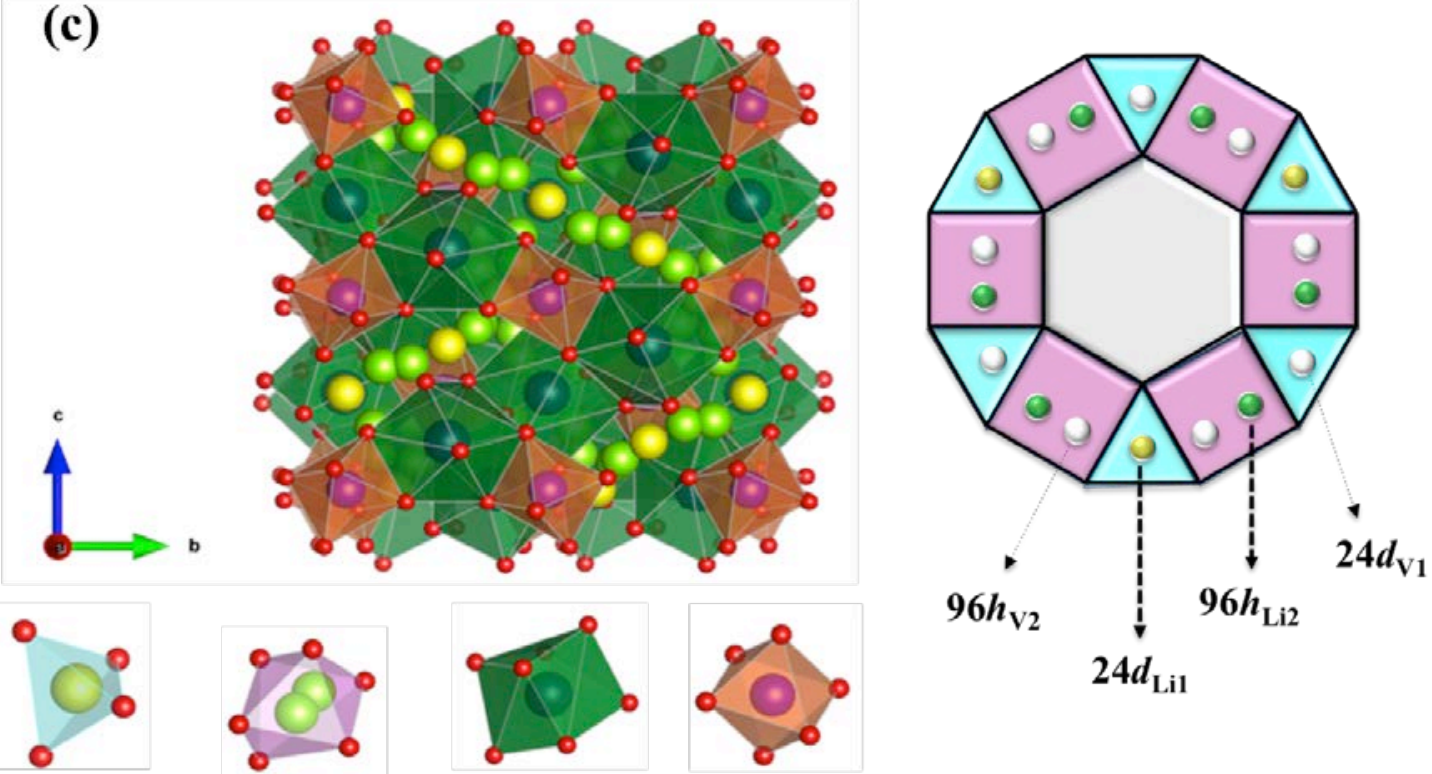

$\mathrm{LiO}_{4}\left(24 d_{\mathrm{Li} 1}\right) \quad \mathrm{LiO}_{6}\left(96 h_{\mathrm{Li} 2}\right) \quad \mathrm{LaO}_{8}(24 c) \quad \mathrm{ZrO}_{6}(16 a)$ 
Fig. 2

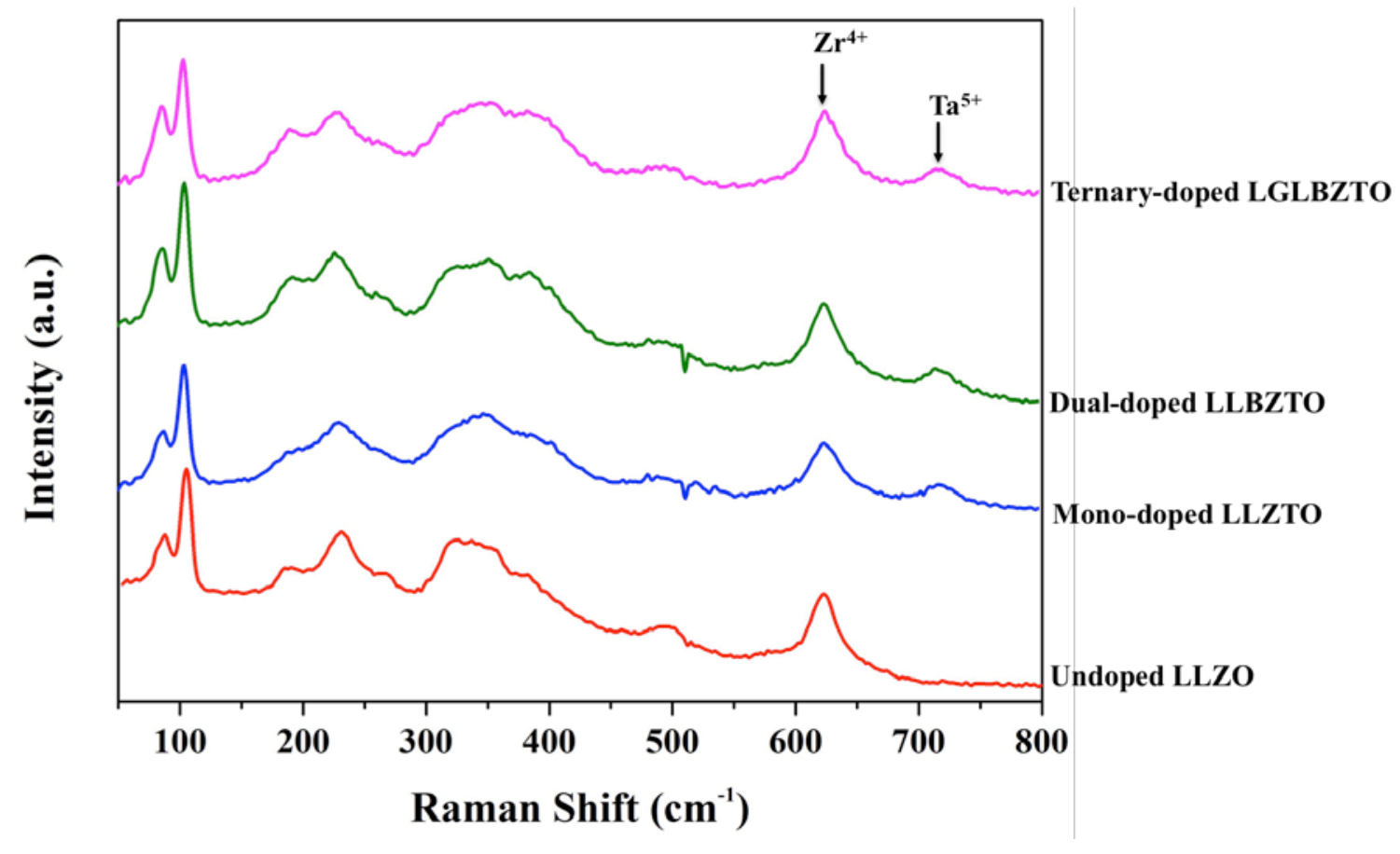


Fig. 3
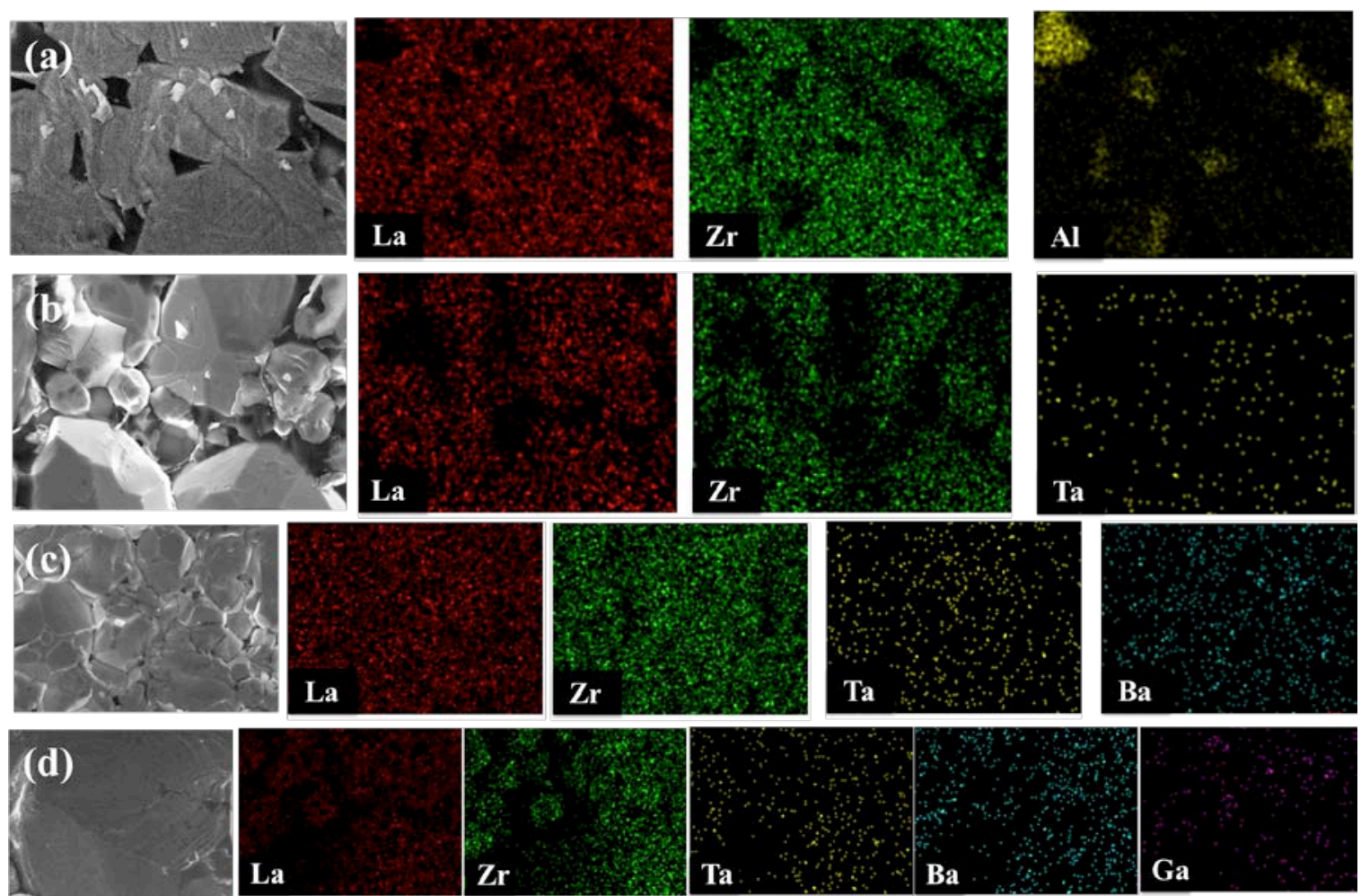
Fig. 4a

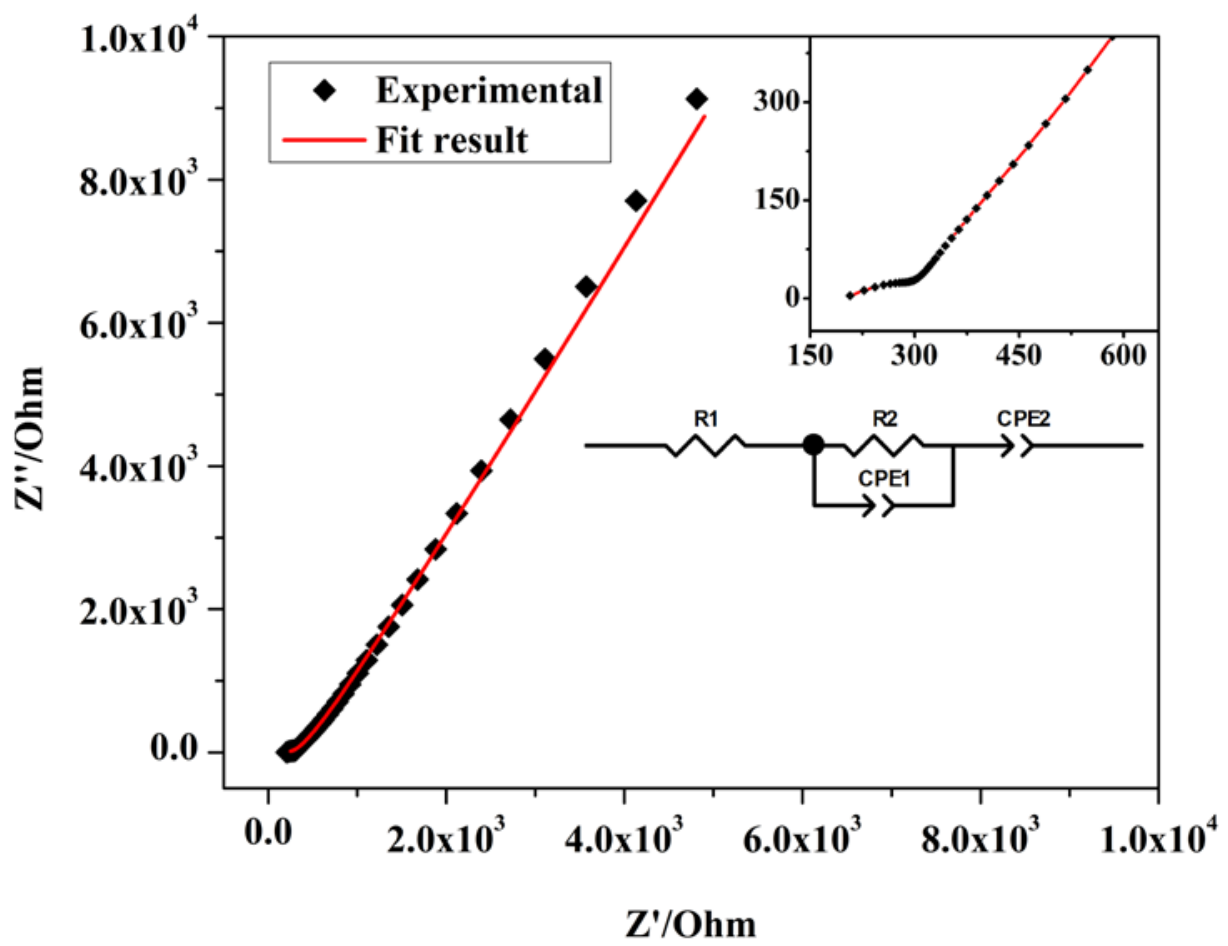

Fig. $4 b$

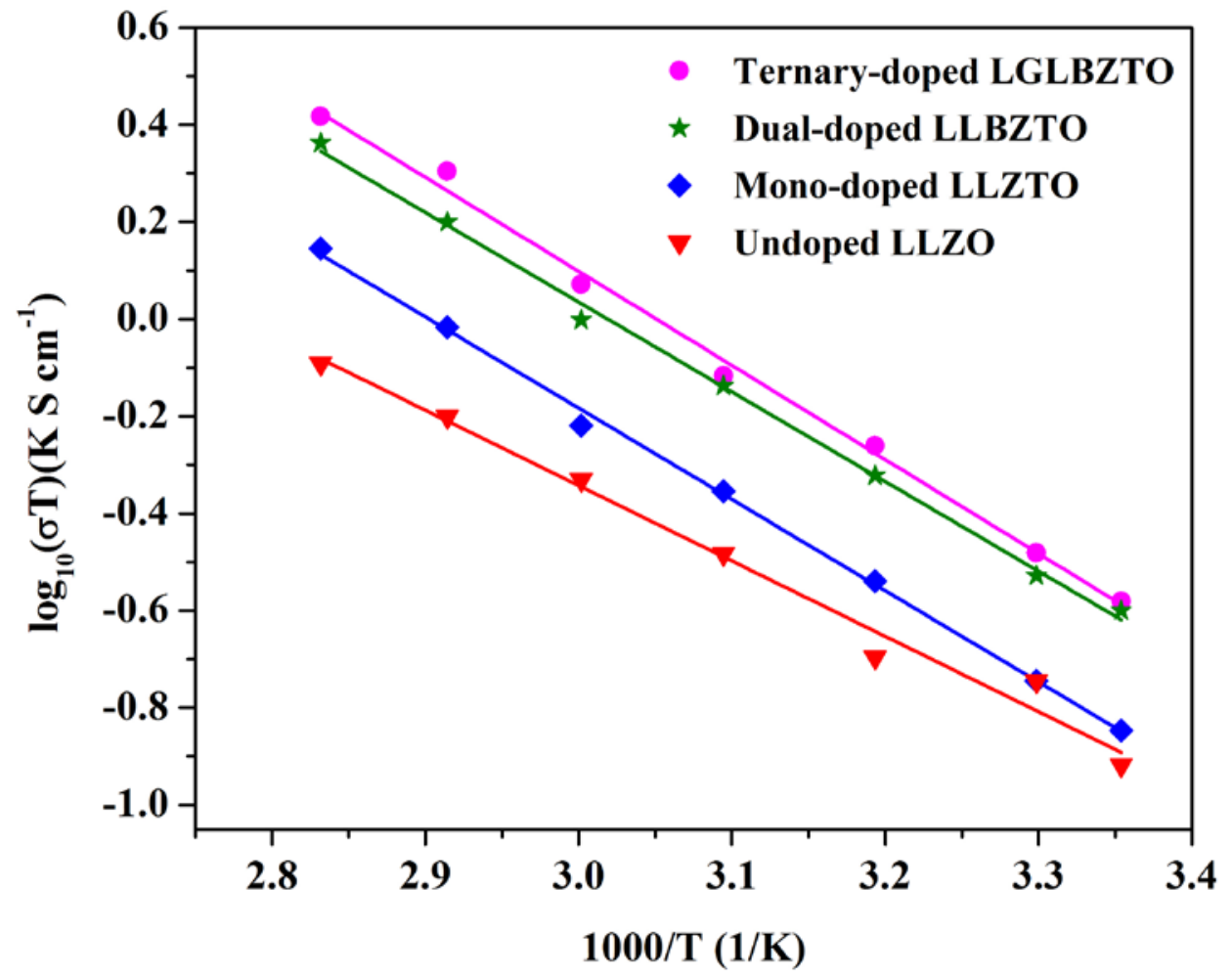


Fig. 5a

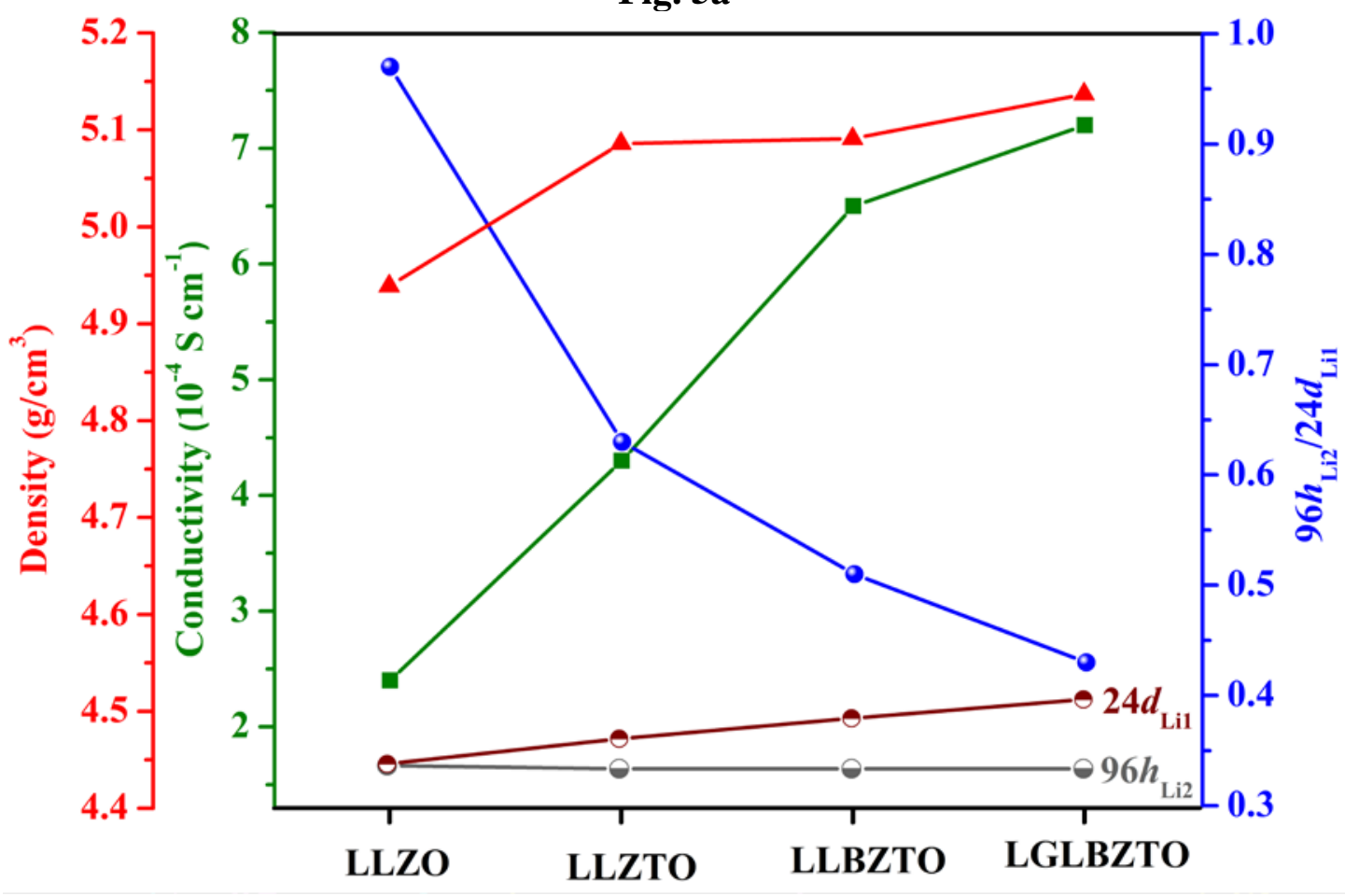

Fig. 5b

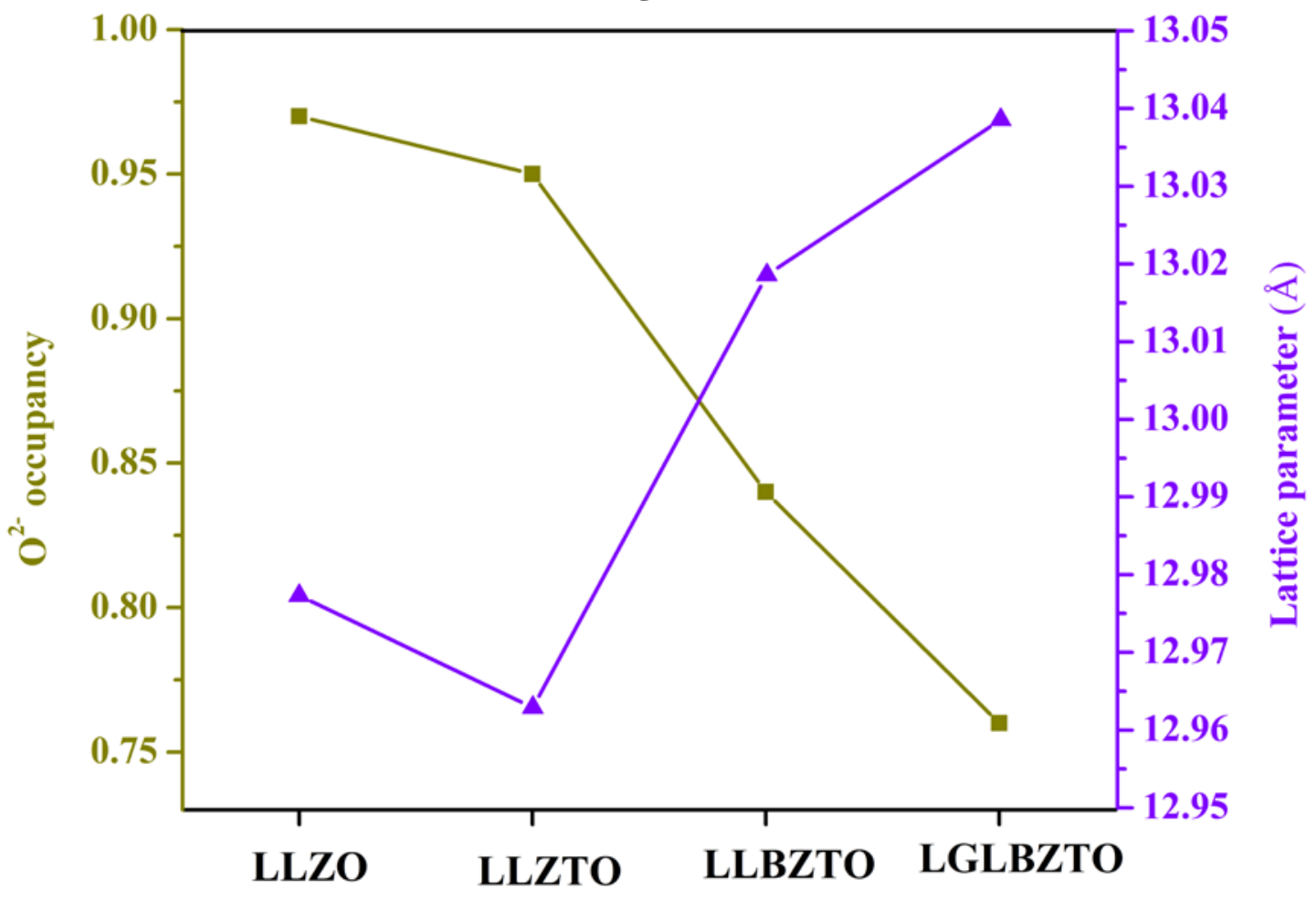


Fig. 6a

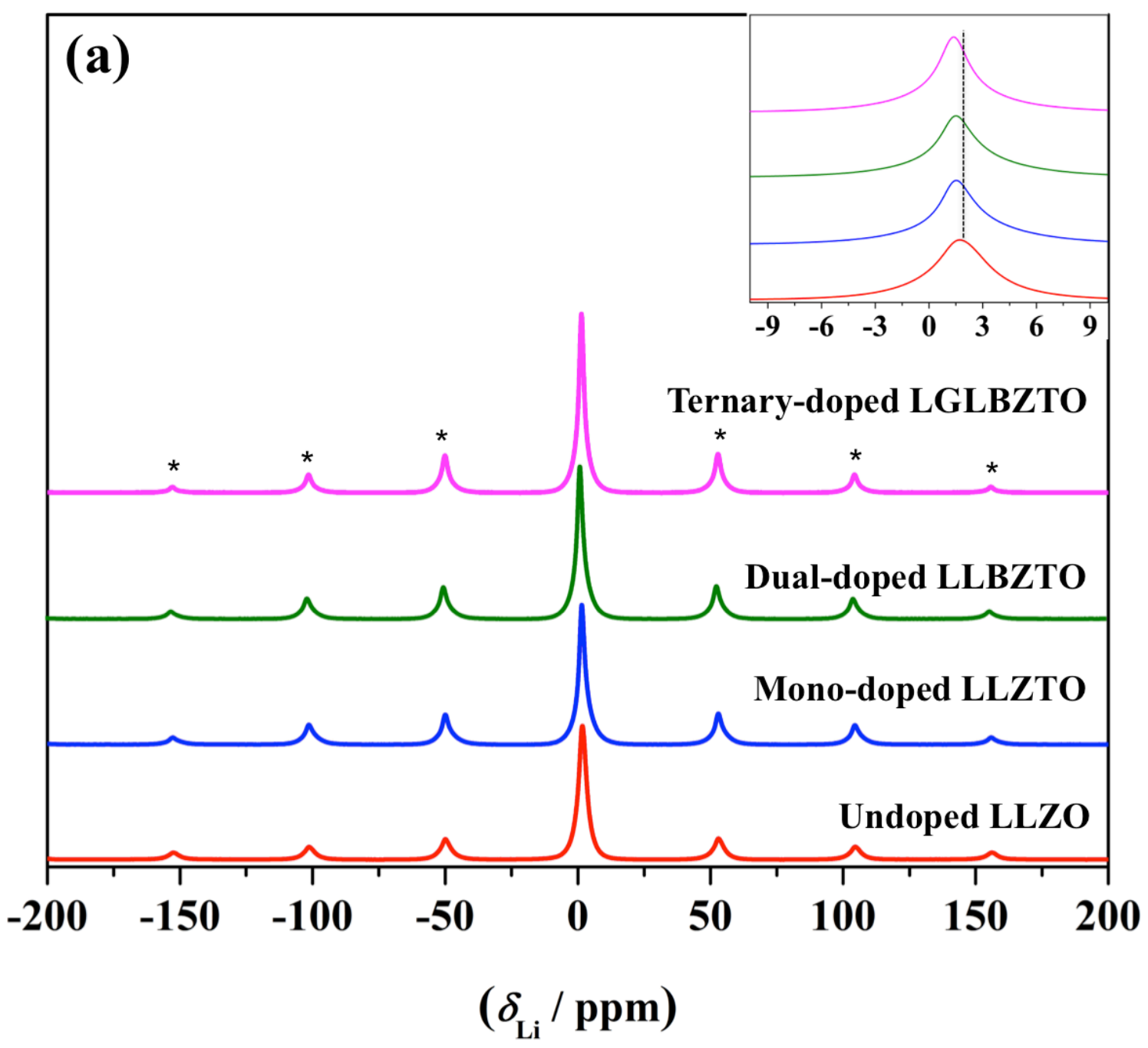


Fig. 6b

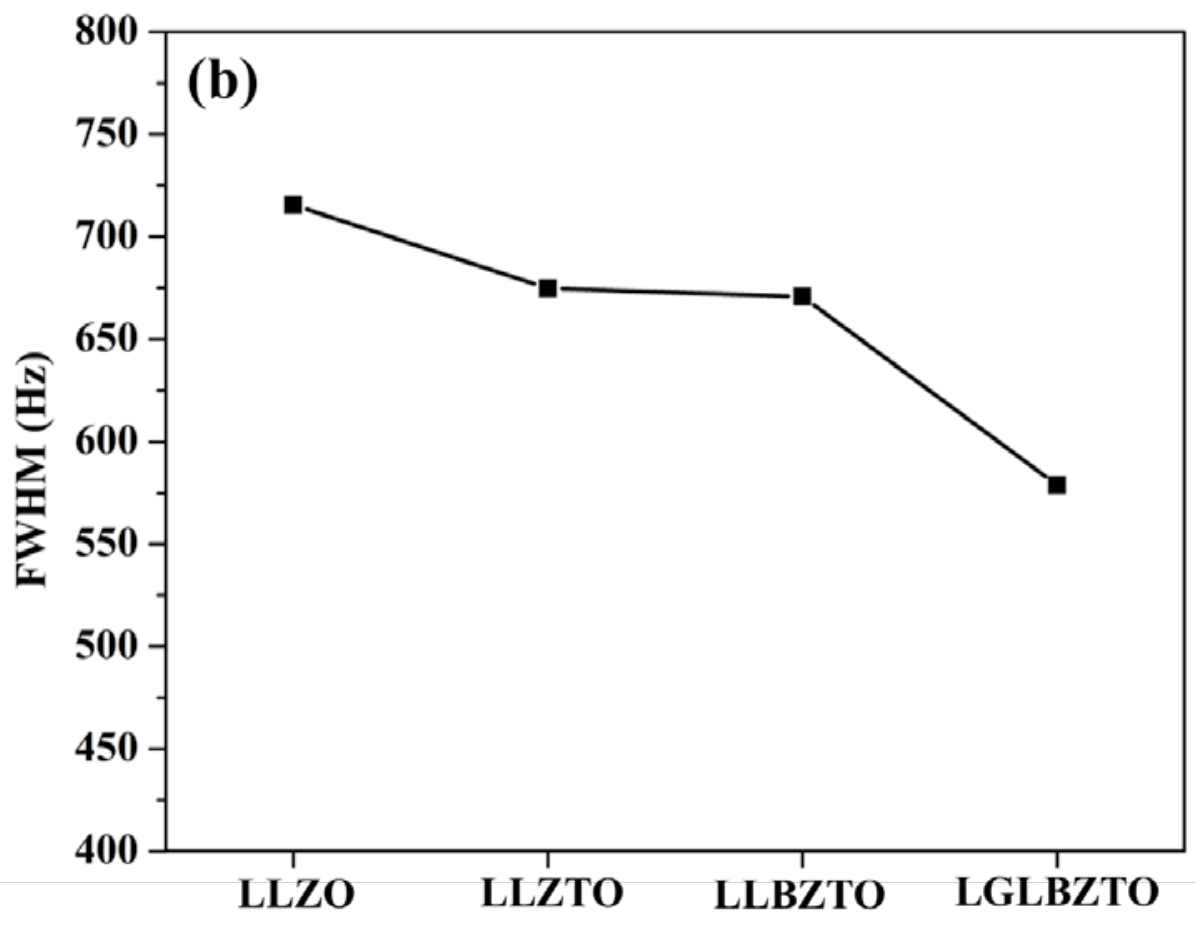

Fig. 6c

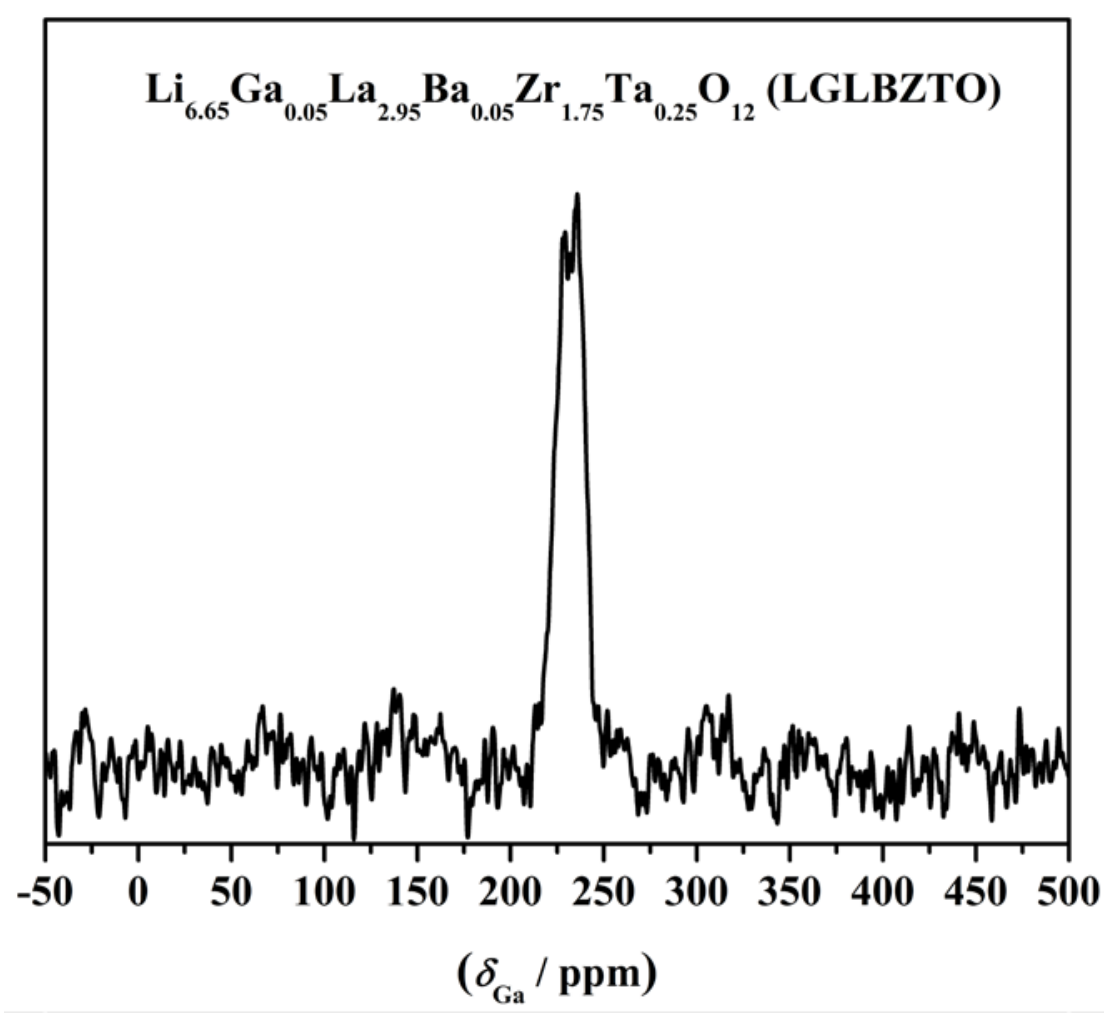


Fig. 7a

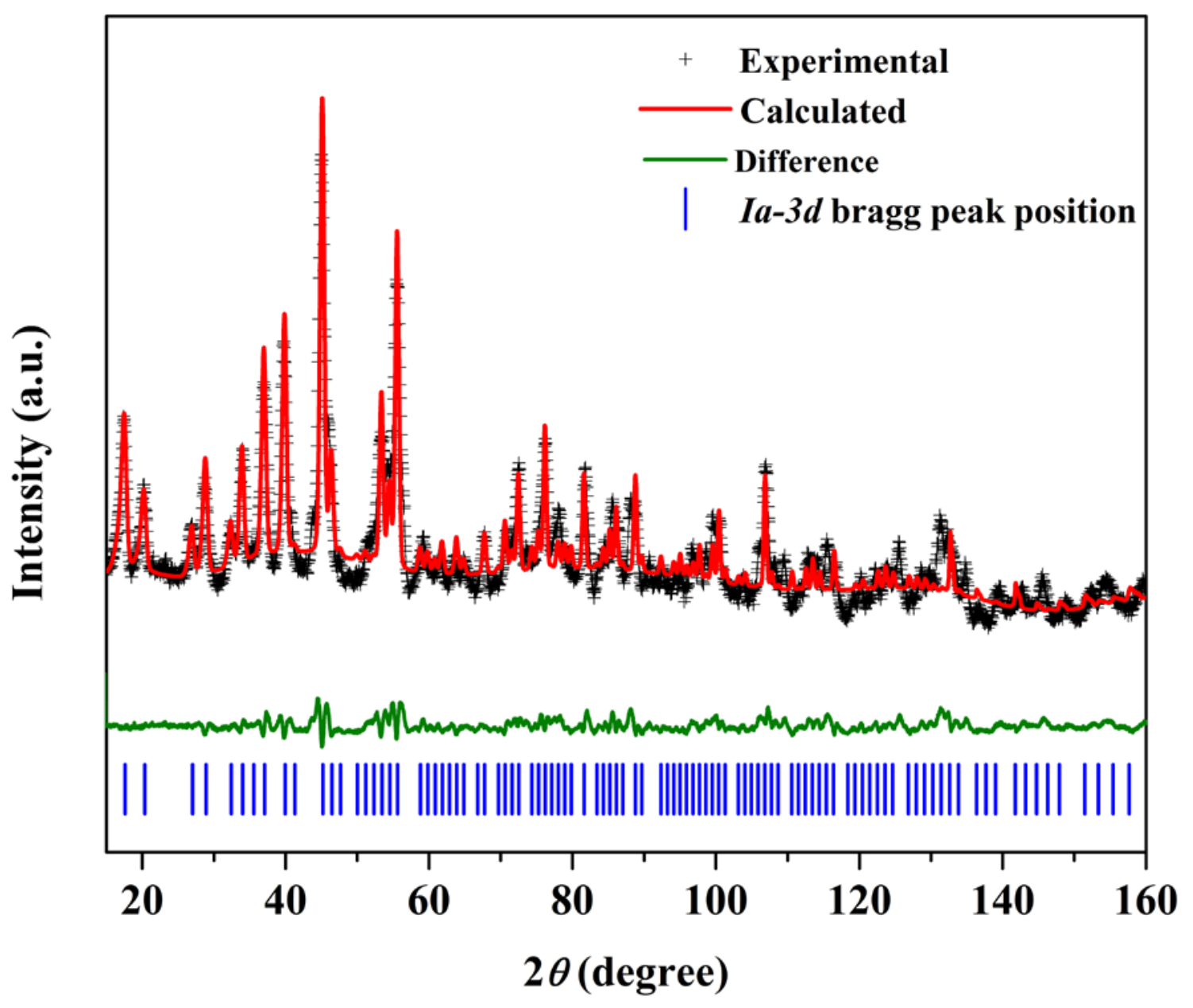


Fig. 7b

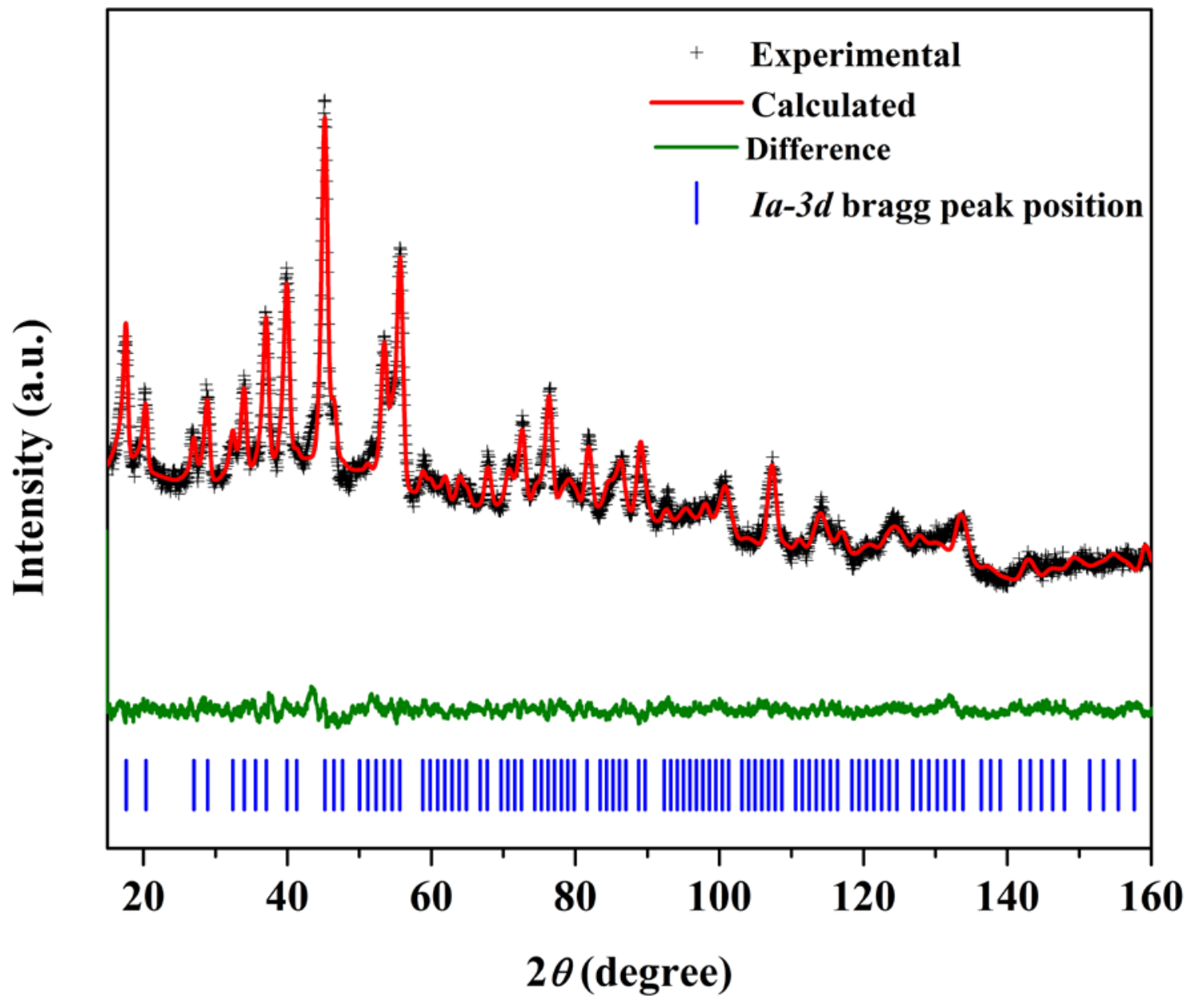


Fig. 7c

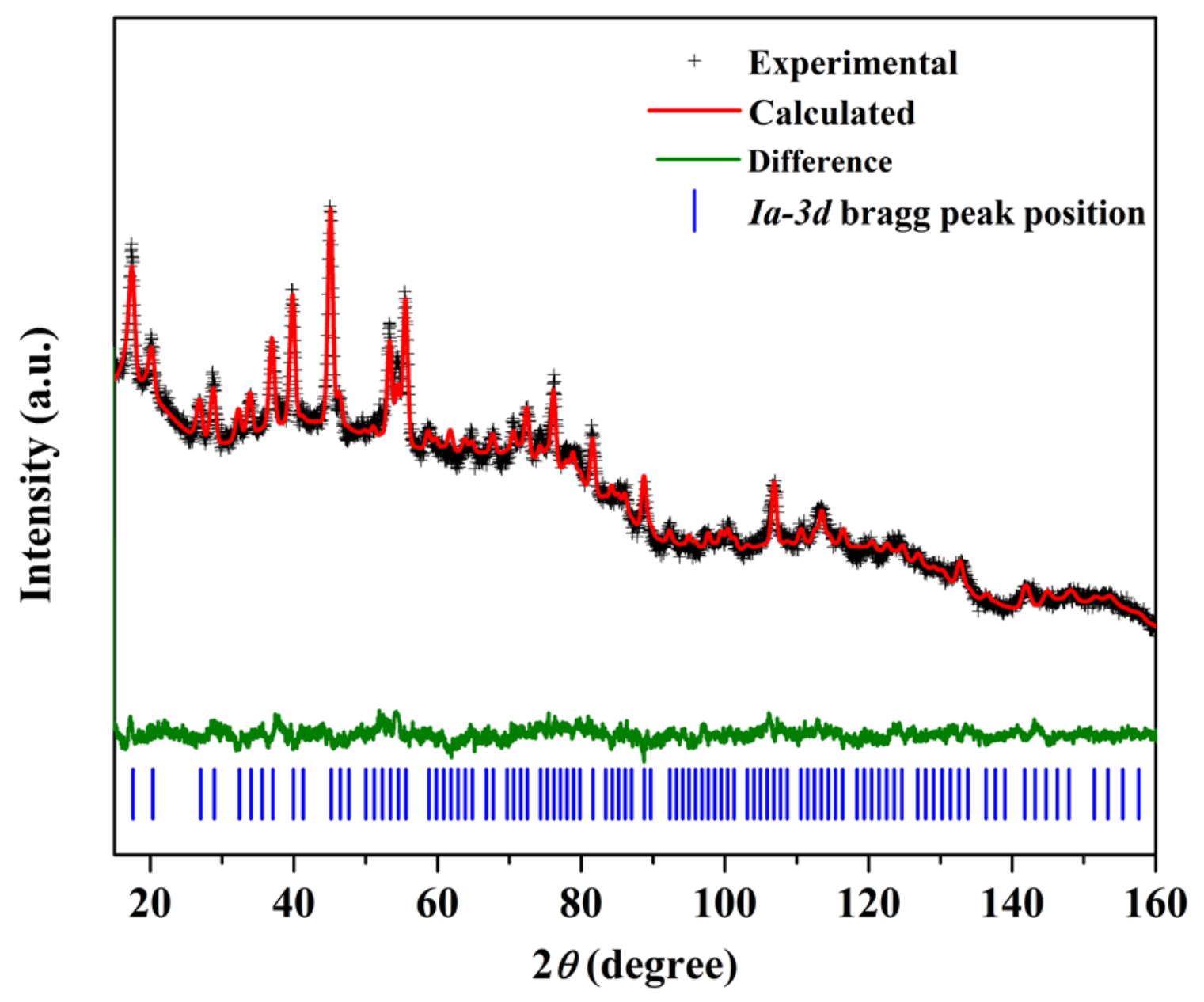


Fig. 7d

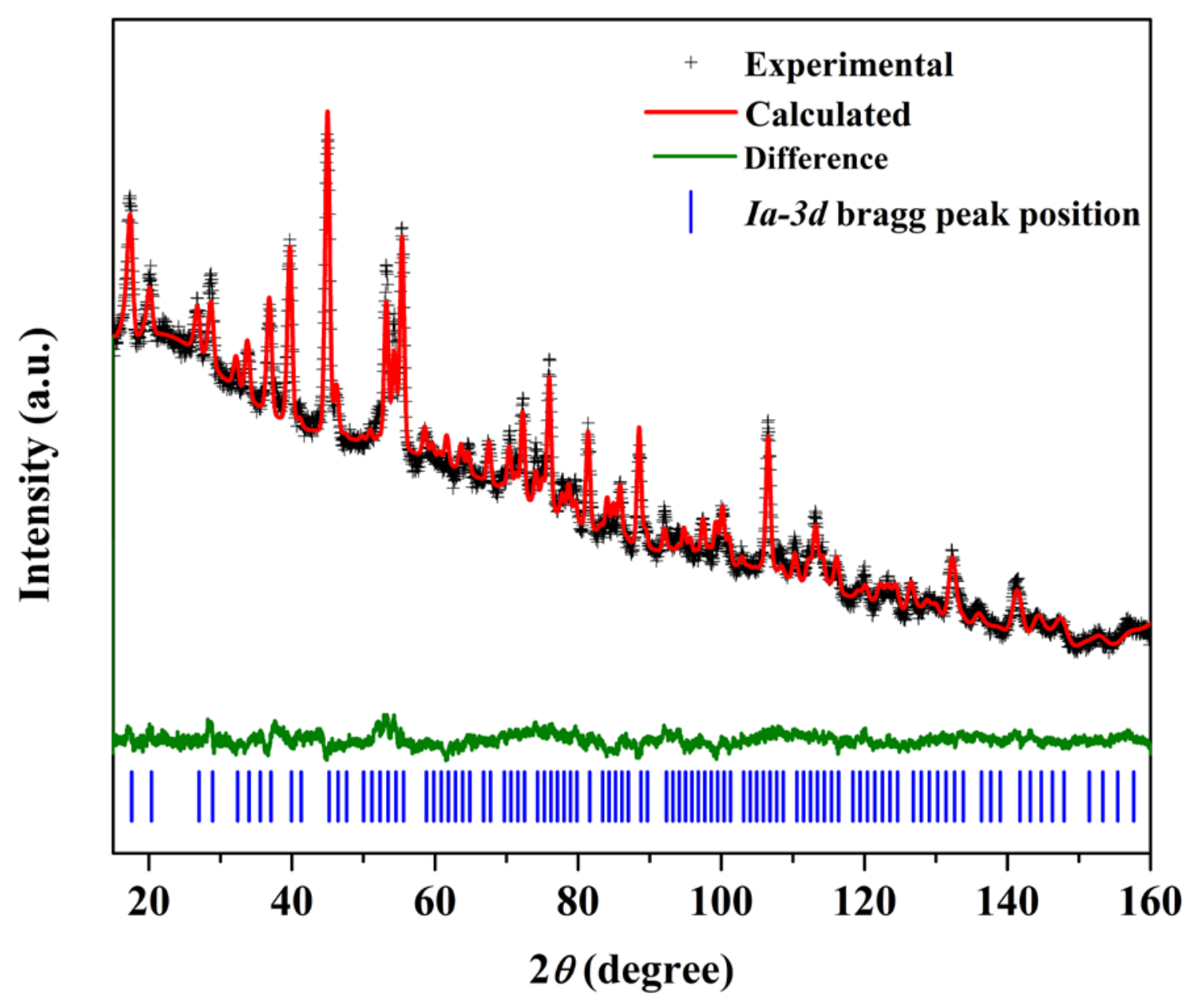


Fig. 8a

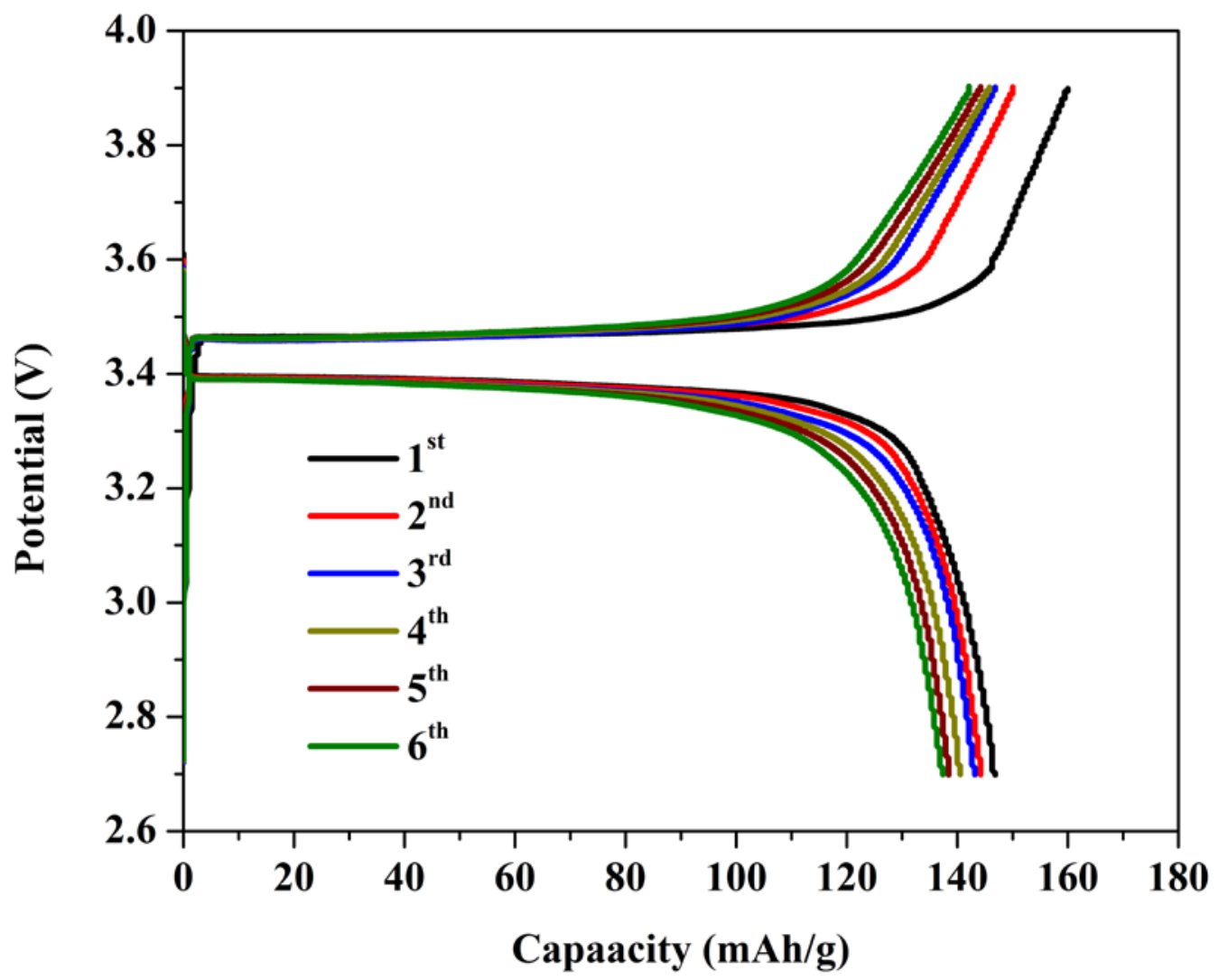

Fig. 8b

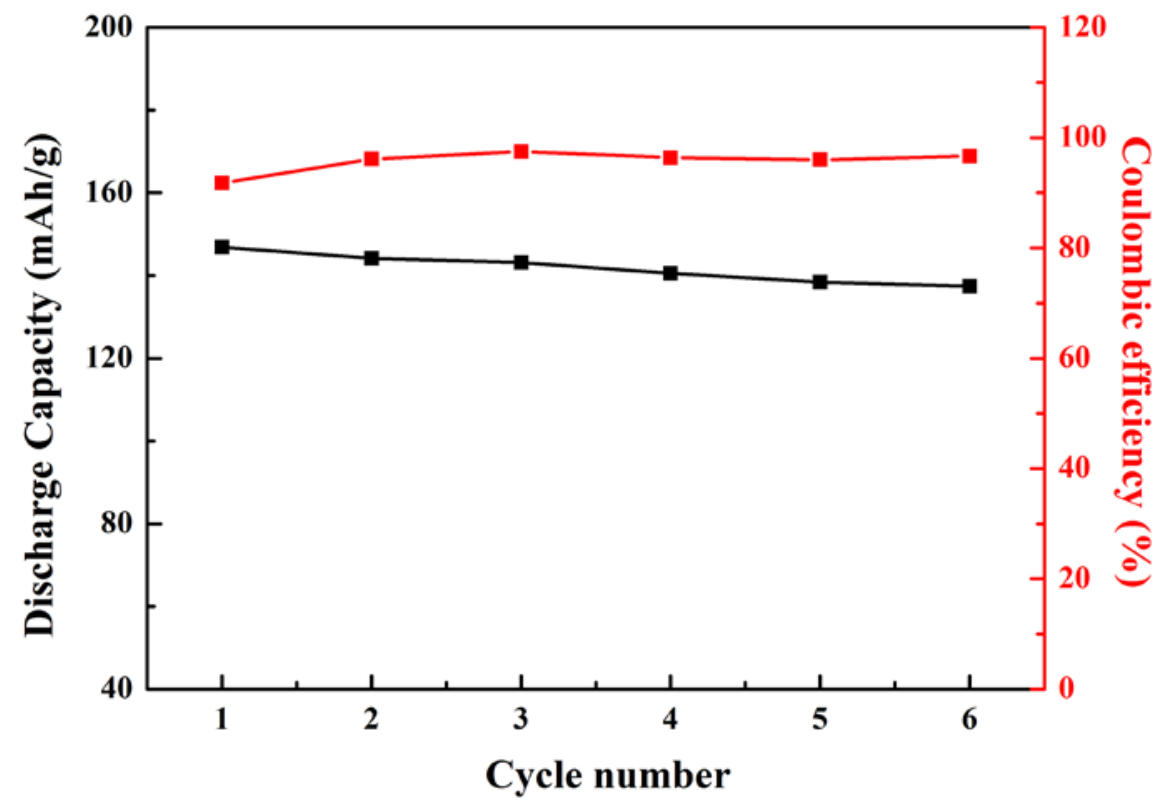


A systematically multi-doping strategy approached to enhance the Li-ion conductivity of garnet-type solid electrolyte $\mathrm{Li}_{7} \mathrm{La}_{3} \mathrm{Zr}_{2} \mathrm{O}_{12}$ by doping multi-ions, $\mathrm{Ga}$, $\mathrm{Ba}$ and $\mathrm{Ta}$ into the garnet framework.

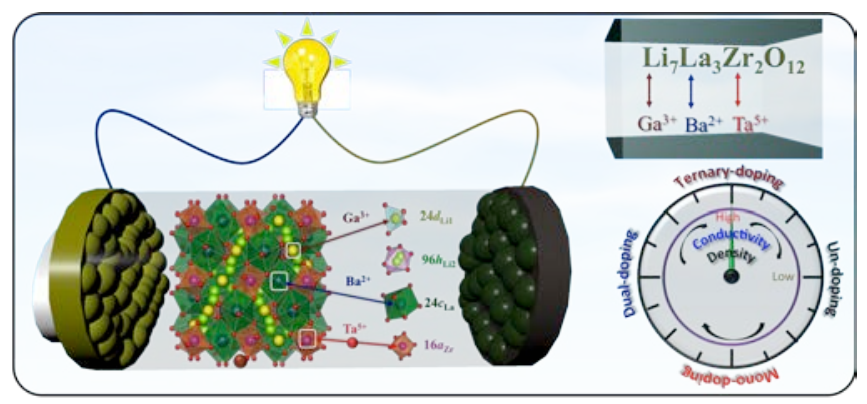

